\title{
Fermentation couples Chloroflexi and sulfate-reducing bacteria to Cyanobacteria in hypersaline microbial mats
}

\author{
Jackson Z. Lee ${ }^{1,2 *}$, Luke C. Burow ${ }^{1,3}$, Dagmar Woebken ${ }^{1,3+}$, R. Craig Everroad ${ }^{1}$, Mike D. Kubo $^{1,4}$, \\ Alfred M. Spormann ${ }^{3}$, Peter K. Weber ${ }^{5}$, Jennifer Pett-Ridge ${ }^{5}$, Brad M. Bebout $^{1}$ and Tori M. Hoehler ${ }^{1}$ \\ 1 Exobiology Branch, NASA Ames Research Center, Moffett Field, CA, USA \\ 2 Bay Area Environmental Research Institute, Sonoma, CA, USA \\ ${ }^{3}$ Departments of Civil and Environmental Engineering, and Chemical Engineering, Stanford University, Stanford, CA, USA \\ ${ }^{4}$ The SETI Institute, Mountain View, CA, USA \\ ${ }^{5}$ Lawrence Livermore National Lab, Chemical Sciences Division, Livermore, CA, USA
}

\section{Edited by:}

Donald A. Bryant, The Pennsylvania State University, USA

Reviewed by:

Niels-Ulrik Frigaard, University of

Copenhagen, Denmark

John R. Spear, Colorado School of

Mines, USA

*Correspondence:

Jackson Z. Lee, NASA Ames

Research Center, PO Box 1, MS

239-4, Moffett Field, CA 94035, USA

e-mail: jackson.z.lee@nasa.gov

${ }^{\dagger}$ Present address:

Dagmar Woebken, Division of Microbial Ecology, Department of

Microbiology and Ecosystem

Science, University of Vienna,

Vienna, Austria
Past studies of hydrogen cycling in hypersaline microbial mats have shown an active nighttime cycle, with production largely from Cyanobacteria and consumption from sulfate-reducing bacteria (SRB). However, the mechanisms and magnitude of hydrogen cycling have not been extensively studied. Two mats types near Guerrero Negro, Mexico-permanently submerged Microcoleus microbial mat (GN-S), and intertidal Lyngbya microbial mat (GN-I)-were used in microcosm diel manipulation experiments with 3-(3,4-dichlorophenyl)-1,1-dimethylurea (DCMU), molybdate, ammonium addition, and physical disruption to understand the processes responsible for hydrogen cycling between mat microbes. Across microcosms, $\mathrm{H}_{2}$ production occurred under dark anoxic conditions with simultaneous production of a suite of organic acids. $\mathrm{H}_{2}$ production was not significantly affected by inhibition of nitrogen fixation, but rather appears to result from constitutive fermentation of photosynthetic storage products by oxygenic phototrophs. Comparison to accumulated glycogen and to $\mathrm{CO}_{2}$ flux indicated that, in the GN-I mat, fermentation released almost all of the carbon fixed via photosynthesis during the preceding day, primarily as organic acids. Across mats, although oxygenic and anoxygenic phototrophs were detected, cyanobacterial [NiFe]-hydrogenase transcripts predominated. Molybdate inhibition experiments indicated that SRBs from a wide distribution of DsrA phylotypes were responsible for $\mathrm{H}_{2}$ consumption. Incubation with ${ }^{13} \mathrm{C}$-acetate and NanoSIMS (secondary ion mass-spectrometry) indicated higher uptake in both Chloroflexi and SRBs relative to other filamentous bacteria. These manipulations and diel incubations confirm that Cyanobacteria were the main fermenters in Guerrero Negro mats and that the net flux of nighttime fermentation byproducts (not only hydrogen) was largely regulated by the interplay between Cyanobacteria, SRBs, and Chloroflexi.

Keywords: microbial mats, hydrogen, fermentation, Guerrero Negro, NanoSIMS

\section{INTRODUCTION}

Hypersaline microbial mats, living analogs of early life on Earth (Des Marais, 2003), are compact and structured laminations of highly diverse microbial communities that undergo significant redox changes over the diel (day-night) cycle, alternating between oxic and anoxic states. The metabolic diversity of microbial mats is reflected in a diverse potential for $\mathrm{H}_{2}$ metabolism (Hoehler, 2005), and nitrogen fixation (Omoregie et al., 2004a,b), and previous work has documented significant efflux of $\mathrm{H}_{2}$ from hypersaline microbial mats (Hoehler et al., 2001; Burow et al., 2012) under dark anoxic conditions. Hence, these systems are of interest not only in an ecological frame of reference, but also for bioenergy science. In previous work we showed that nighttime production of hydrogen gas from hypersaline mats of Elkhorn Slough, CA, USA originated within the photic layer of the mats and was primarily attributable to the fermentation activity of Cyanobacteria, especially the dominant filamentous cyanobacterium Microcoleus chthonoplastes, and was largely insensitive to nitrogen fixation (Burow et al., 2012). In the Elkhorn Slough mats, hydrogen consumers [sulfate-reducing bacteria (SRB)] were present in close physical association with hydrogen producers, and significantly reduced hydrogen efflux (Burow et al., 2013, in press). Understanding the ecological and environmental factors that control net $\mathrm{H}_{2}$ production is thus critical to understanding the role of $\mathrm{H}_{2}$ cycling in mat structure and ecology.

In the present work we have characterized and quantified fermentative activity and consumption of fermentation products in two mat types from the previously documented site at Guerrero Negro, B.C.S., Mexico, that exhibit a range of net $\mathrm{H}_{2}$ production rates. "GN-S" are well-developed subtidal mats located in pond 4 near pond 5 of the salt works and constructed primarily by the cyanobacterium Microcoleus chthonoplastes that have been 
described extensively in previous reports (Spear et al., 2003; Ley et al., 2006; Feazel et al., 2008; and Robertson et al., 2009). "GN-I" are intertidal mat communities constructed largely by Lyngbya sp. The difference in dominant cyanobacterium and extent of development of accessory populations are reflected in differing chemical behavior of the two mat types, including in $\mathrm{H}_{2}$ efflux. Previous work on the GN-I mats documented that the integrated $\mathrm{H}_{2}$ production rate is equivalent to $16 \%$ of net daytime carbon fixation (on a per-electron basis), and individual bubbles at the mat surface may contain up to $10 \%$ hydrogen in the predawn hours (Hoehler et al., 2001; Hoehler, 2005). Moreover, the amount of $\mathrm{H}_{2}$ efflux has been found to vary over more than four orders of magnitude, as a function of environmental forcing (Bebout et al., 2002, 2004; Hoehler, 2005; Burow et al., 2012). In comparison, the submerged mats experience relatively stable conditions and release less $\mathrm{H}_{2}$.

The extensive diversity, dominance patterns, and dynamic microbial response over space and time found within microbial mats are well suited for the development and deployment of advanced sequencing and isotope probing techniques to identify the complex biological interactions as well as energy and nutrient cycles of these highly diverse systems. When combined with traditional biogeochemical techniques, these methods can provide insights into energy and nutrient cycling in and through these systems. Using a comparative approach, the relative role of fermentation in the carbon and hydrogen cycles of these two mat types, and the ecology surrounding these cycles, was examined via a holistic set of molecular, isotopic, and biogeochemical methods. Specifically, we employed pyrotag libraries, functional gene sequencing of [ $\mathrm{NiFe}]$-hydrogenase $(h o x H)$ and dissimilatory sulfite reductase $(d s r A)$, stable isotope probing of labeled ${ }^{13} \mathrm{C}$-bicarbonate and ${ }^{13} \mathrm{C}$-acetate, Catalyzed Reporter Deposition Fluorescence In Situ Hybridization (CARD-FISH) probing of Chloroflexi and SRB clades, in combination with measurements of hydrogen, hydrogen sulfide, and organic acids to examine microbial mats manipulated with inhibitors that disrupt the sulfur, nitrogen, and carbon cycles. The results from these experiments indicated that in GN-I mats constitutive fermentation served to liberate roughly $80 \%$ of the photosynthetically fixed electrons into the bulk pool and thereby formed a basis for close trophic coupling between Cyanobacteria, filamentous anoxygenic phototrophs, and SRBs in hypersaline mats of both Guerrero Negro and of Elkhorn Slough.

\section{MATERIALS AND METHODS FIELD SITE AND SAMPLE COLLECTION}

Water and whole $30 \times 30 \mathrm{~cm}$ sections of microbial mats were harvested in September 2010 and September 2011 from sites located near Guerrero Negro, B.C.S. Mexico. Two distinct mat types were selected for study. Mats from the seawater concentration area (pond 4 near 5) of the Exportadora de Sal, S.A. (ESSA) Guerrero Negro, B.C.S. saltworks $\left(27^{\circ} 41^{\prime} 20.6^{\prime \prime} \mathrm{N}, 113^{\circ} 55^{\prime} 1.2^{\prime} \mathrm{W}\right)$ have a well-documented community profile (Spear et al., 2003; Ley et al., 2006; Feazel et al., 2008; and Robertson et al., 2009). These mats have experienced a largely quiescent environment with permanent cover of approximately $0.5-1 \mathrm{~m}$ of water at $\sim 80-100 \% 0$ salinity, and can grow to approximately $10 \mathrm{~cm}$ thick (Des Marais, 1995; Nübel et al., 1999). This mat type, which is constructed primarily by the cyanobacterium Microcoleus chthonoplastes is referred in this study as "GN-S" (Guerrero Negro-Submerged). The second mat type was collected from the intertidal flats bordering Laguna Ojo de Liebre, just outside the ESSA salt works $\left(27^{\circ} 45^{\prime} 30.2^{\prime \prime} \mathrm{N}, 113^{\circ} 59^{\prime} 42.8^{\prime \prime} \mathrm{W}\right)$, and is referred to as "GN-I" mats (Guerrero Negro-Intertidal). The GN-I mats, constructed primarily by the cyanobacterium Lyngbya spp., experience periodic tidal desiccation and breakup along a sandy sloping shore ecological gradient (Rothrock and Garcia-Pichel, 2005). Mats were also collected from Elkhorn Slough, CA, USA in November 2011 in order to facilitate comparison of the present work with previously published studies of microbial mat fermentation and $\mathrm{H}_{2}$ production and consumption (Burow et al., 2012; Woebken et al., 2012). Samples were returned to a greenhouse facility at NASA Ames and maintained in UV transparent acrylic boxes under $\sim 3 \mathrm{~cm}$ of water collected from the site specific to the individual mat types as previously described (Bebout et al., 2002). The mats received natural solar irradiance and regulated temperature environment designed to mimic natural daily fluctuations around the in situ average of $\sim 19^{\circ} \mathrm{C}$.

\section{DIEL MANIPULATIONS}

Diel (24 hour) studies of these mat types were performed with inhibitors of specific metabolic processes and in conjunction with physical disruption by homogenization, all conducted under natural light conditions. All manipulations were performed by placing replicate $11 \mathrm{~mm}$ diameter cores of the top $2 \mathrm{~mm}$ of the microbial mats into $14 \mathrm{ml}$ glass serum vials with $4 \mathrm{ml}$ site water. Bottles were closed with butyl rubber stoppers, crimp sealed, flushed with nitrogen gas, and incubated under controlled temperature (Burow et al., 2012). Six replicates were prepared for each experimental condition. The four distinct manipulation experiments were:

(1) DCMU [3-(3,4-dichlorophenyl)-1,1-dimethylurea, a specific inhibitor of Photosystem II (Oremland and Capone, 1988; Oettmeier, 1992), and therefore of oxygenic photosynthesis] was used to evaluate the contribution of oxygenic photosynthetic carbon fixation as a driver of the release of fermentation products. DCMU was added to mats at dawn at a final concentration of $20 \mu \mathrm{M}$.

(2) Ammonium chloride was added as a source of combined nitrogen in order to suppress dinitrogen-fixing activity (Bebout et al., 1987; Burow et al., 2012) and thereby investigate whether $\mathrm{N}$-fixation activity (and associated energy demand) affected rates of fermentation. Ammonium chloride was added at dusk at a final concentration of $8.8 \mathrm{mM}$.

(3) Sodium molybdate, a competitive inhibitor of sulfate reduction (Oremland and Capone, 1988), was used to quantify the role of sulfate reducers in consuming fermentation products. Sodium molybdate was added to mat incubations in site water and in sulfate-free artificial ASN5 media (to enhance the competitive effect) at dusk at a final concentration of $30 \mathrm{mM}$.

(4) Mat microbes were physically disrupted from each other with a Tissue Master (TM125-115, Omni International, Kennesaw, GA, USA) in order to investigate the importance of close spatial associations between microbes in internal cycling 
vs. diffusive loss of fermentation products (Burow et al., in press).

\section{BIOGEOCHEMICAL METHODS}

\section{Analysis of $\mathrm{H}_{2}$ and organic acids}

To measure $\mathrm{H}_{2}$ net flux, $25 \mu \mathrm{L}$ of headspace was withdrawn with a volumetric syringe from the headspace of each replicate microcosm vial at several time points during an incubation period. Samples were either analyzed immediately by direct injection onto a gas chromatograph with an $\mathrm{HgO}$ reduction detector (Trace Analytical) (Burow et al., 2012), or were preserved for later analysis as a small $(1 \mathrm{~mL})$ gas sample in a serum vial containing saturated $\mathrm{NaCl}$ solution that had been sparged with nitrogen gas for $20 \mathrm{~min}$. To analyze organic acids, the entire liquid phase $(4 \mathrm{~mL})$ of each of three replicate microcosms for each control or manipulation experiment was sampled (with the associated incubation sacrificed). Liquid was filtered through $0.2 \mu \mathrm{m}$ syringe filters for storage in ashed glass vials at $-20^{\circ} \mathrm{C}$. Organic acids (C1-C5) were quantified via high-pressure liquid chromatography (Albert and Martens, 1997).

\section{Analysis of glycogen, Dissolved Inorganic Carbon (DIC), and hydrogen sulfide}

Whole $1-\mathrm{cm}$ diameter subcores were collected from incubated microbial mats and immediately frozen in liquid nitrogen. The uppermost $2 \mathrm{~mm}$ was sub-sectioned while still frozen and was subsequently freeze dried. The dried samples were ground and sonicated (3 min, setting 6, Fisher 60 Dismembrator) and transferred to a $7 \mathrm{ml}$ glass screwcap vial. The vial was then capped and put in a boiling water bath for 6 min to solubilize glycogen and stop any enzyme activity in the extract. $50 \mu$ l of the extract was filter sterilized $(0.45 \mu \mathrm{m})$ and added to $50 \mu \mathrm{l}$ of amyloglucosidase solution (Keppler and Decker, 1974) $(0.01 \mathrm{~g}$ in $2 \mathrm{ml}$ deionized water) in a $1.5 \mathrm{ml}$ screwcap vial. The vial was placed horizontally in a $40^{\circ} \mathrm{C}$ heating block on an orbital shaker so that the vial could roll slightly to aid mixing. After $1 \mathrm{~h}$, the vial received $100 \mu \mathrm{l}$ of a derivatization solution consisting of $60 \mathrm{mg}$ anthranilamide (Sigma-Aldrich, St. Louis, MO, USA), $40 \mathrm{mg}$ sodium cyanoborohydride (Sigma-Aldrich), $0.6 \mathrm{ml}$ glacial acetic acid and $1.4 \mathrm{ml}$ dimethyl sulfoxide (Bigge et al., 1995) and then heated to $70^{\circ} \mathrm{C}$ for $1 \mathrm{~h}$ followed by isocratic HPLC separation and fluorescence detection ( $270 \mathrm{~nm}$ excitation, $430 \mathrm{~nm}$ emission). The solvent consisted of $20 \mathrm{ml}$ tetrahydrofuran, $6 \mathrm{ml}$ butylamine, $10 \mathrm{ml}$ phosphoric acid, $12 \mathrm{ml}$ tetraethyl ammonium hydroxide and $3950 \mathrm{ml}$ deionized water (Anumula, 1994).

DIC was quantified in separate flux chamber experiments of whole mats based on the methods of Hoehler et al. (2001). $1.5 \mathrm{~mL}$ fluid samples were collected in $3 \mathrm{~mL}$ plastic syringes from $1.5 \mathrm{~L}$ flux chambers placed on mats in the greenhouse, closed by means of a 3-way stopcock, and stored at $4^{\circ} \mathrm{C}$ until analysis (typically within $2-3 \mathrm{~h}$, but in no case greater than $48 \mathrm{~h}$ after collection). Samples were analyzed via flow injection analyzer (FIA) (Hall and Aller, 1992). Duplicate injections were made for each incubation time point but, due to limited volume of incubation fluids, replicate samples were not taken.

Hydrogen sulfide measurements were based on the work of Cline (1969) and consisted of a
$N, N$-Dimethyl-p-phenylenediamine sulfate salt and iron(III) chloride colorimetric method (read at $670 \mathrm{~nm}$ ) with a sodium sulfide standard.

\section{PHOTOSYNTHESIS/FERMENTATION MASS AND ELECTRON BALANCE}

Net flux data collected from several diel experiments were used to estimate the proportion of photosynthetic carbon uptake that was subsequently mobilized in fermentation. We compared DIC uptake and flux of fermentation products on the common basis of "electron equivalents" to enable us to include $\mathrm{H}_{2}$ in the calculation. The flux amounts were used to determine total daytime and nighttime DIC flux and averaged to obtain the average flux of inorganic carbon taken up and released by mats over a single diel cycle. Glycogen day and night differences were averaged and used to estimate net fixed carbon accumulation and depletion. Net and total production of organic acids and hydrogen were estimated, respectively, from replicated control and physical disruption experiments. All fluxes were normalized to the surface area of incubated mat cores and then converted to "electron equivalents" based on total charge state $\left[\left(\mathrm{CH}_{2} \mathrm{O}\right)_{\mathrm{n}}=4 \mathrm{n}\right.$, $\mathrm{CH}_{3} \mathrm{COOH}=8$, etc.] of each chemical species. Photoautotrophy was assumed to fix four electrons per carbon. Standard deviations were distributions of replicate measurements propagated to final results.

\section{MOLECULAR BIOLOGY METHODS}

\section{Nucleic acid isolation and pyrotag sequencing of $16 S$ Small} Subunit (SSU) rRNA genes and transcripts

In October 2011 (1 month after field collection), samples for pyrotag libraries of both GN mat types were collected at $1200-2400 \mathrm{~h}$ from unaltered mats kept in site water in a greenhouse environment. Nucleic acid extraction [RNA clean extractions for nucleic acids (DNA and RNA) followed by cDNA reverse-transcription] was performed as per Burow et al. (2012). The upper $2 \mathrm{~mm}$ phototrophic layer was homogenized and extracted using acid-phenol and DNA/RNA cleanup and separation with the Qiagen RNeasy Mini Kit and the QIAamp DNA Mini Kit as per the manufacturers' protocol (Qiagen, Venlo, The Netherlands). Extractions were done in triplicate and pooled. The V8 hypervariable region of the 16S SSU rRNA gene was amplified from DNA (rRNA gene) or cDNA (rRNA reverse-transcript) templates using the universal primer pair 926f/1392r (Engelbrektson et al., 2010), including the titanium adaptor sequences and a fivebase barcode on the reverse primer. Sequencing and bioinformatics processing was completed by Research and Testing Laboratory, LLC (Lubbock, TX, USA) using an in-house denoising, demultiplexing, clustering, and taxonomic assignment pipeline (http:// www.researchandtesting.com/). Operational Taxonomic Unit (OTU) tables of denoised and dereplicated sequences with taxonomies identified by BLASTN+ on a custom NCBI database were received from the vendor. Taxonomy and taxonomic levels were based on BLAST percent similarity to best match reference sequences (same species $=97 \%$ ID, genus $=95 \%$, etc.). Population statistics were computed using subsampling $(n=$ $100)$ to the smallest library size $(11,500)$ using QIIME (Caporaso et al., 2010) and the average and distribution of Chaol and ACE metrics determined. Interactive Krona HTML5 (Ondov et al., 
2011) hierarchical pie chart community profiles of all pyrotag libraries have been included in the supplemental information online as Krona_charts_supplemental.zip.

\section{Degenerate bidirectional [NiFe]-hydrogenase (hoxH) and dissimilatory sulfite reductase (dsrA) gene sequencing}

Primers HoxH_F37 (5' -ATHGARGGHCAYGCBAARAT-3') and HoxH_R518 (5' -ACNCCICCVGGNAYHGHCCA-3') developed to amplify reversible nickel-iron (type $3 \mathrm{~b}$ ) hydrogenase transcripts containing the L1 and L2 motifs (Vignais and Billoud, 2007) and used previously (Burow et al., 2012) were used to sequence hydrogenases from both mat types from nighttime manipulations (2 96-well plates each from GN-I and GNS). Primers dsrA_1R (5'-ACSCACTGGAAGCACG-3') (Wagner et al., 1998) and dsrA_DGGE_R (5' - CGGTGMAGYTCRTC - 3') (Leloup et al., 2009) designed to detect sulfate reduction capability from SRBs were used to sequence $d s r A$ genes from both mat types in nighttime manipulations (Burow et al., in press) (2 cDNA and 1 DNA 96-well plates each from GN-I and GN-S). PCR and cloning (described in Burow et al., 2012) were used to prepare 96-well format clone libraries of both DNA and cDNA for expression ratio profiling. Sequencing was completed using Single Pass T3 primer end sequencing runs at Beckman Coulter Genomics (Danvers, MA, USA) using BigDye Terminator v3.1 sequencing on an ABI PRISM 3730xl (Life Technologies, Carlsbad, CA, USA).

\section{Phylogenetic analysis of bidirectional [NiFe]-hydrogenase (hoxH) and dissimilatory sulfite reductase (dsrA) clone sequences}

All sequences were quality trimmed (Q30, 10-base average), and filtered for primer and plasmid regions and translated to the amino acid coding frame using Geneious (Biomatters, Auckland, New Zealand). Sequences were exported and then clustered by CD-HIT (Li and Godzik, 2006) at the 97\% similarity level and queried against the NCBI non-redundant peptide database using the Basic Local Alignment Search Tool (BLAST) (Altschul et al., 1990). Sequences were then aligned to custom databases composed of reference $d s r A$ or hoxH sequences from environmental samples and isolated bacteria using CLUSTALX2 (Larkin et al., 2007) and then manually curated. The final alignment, excluding gapped positions, included 134 residues for 40 OTUs and 84 reference sequences for $d s r A$ and 156 residues for 17 OTUs and 46 reference sequences for hoxH. For hoxH genes, 4 high-variability amino acid positions in the alignment $(<50 \%$ conserved $)$ were removed from the alignment. For each gene, maximum likelihood phylogenetic trees were constructed using PhyML (Guindon et al., 2010) with the $L G+I+G$ substitution matrix as selected using the AIC criterion using Prottest 2.4 (Abascal et al., 2005; Le and Gascuel, 2008). Neighbor-joining was performed in MEGA5.2 (Tamura et al., 2011) using the JTT+I+G substitution matrix (Jones et al., 1992), which was the best-fit matrix available, as determined by Prottest. ML and NJ analyses underwent 100 and 1000 bootstrap iterations, respectively. Deeply branching or closely related reference sequences were pruned from trees for readability.

\section{DATA ARCHIVING}

Representative clone sequences of hoxH and dsrA OTUs were submitted to GenBank as accession KF582421-KF582479. Pyrotag libraries were submitted as *.sff files to NCBI's Sequence
Read Archive (SRA) under BioProject PRJNA219681 (accession SRP030038).

\section{ISOTOPE LABELING METHODS \\ ${ }^{13} \mathrm{C}$-Bicarbonate and ${ }^{13} \mathrm{C}$-acetate labeling of GN mats and isotope-ratio mass spectrometry (IRMS)}

Small subcores (11-mm diameter, 2-mm depth) of each microbial mat type were cut from whole sections of intact microbial mat and placed in serum vials with $4 \mathrm{ml}$ site water. ${ }^{13} \mathrm{C}$-bicarbonate was added for 10 daytime hours to examine autotrophic lightdriven incorporation. $\left[2-{ }^{13} \mathrm{C}\right]$-acetate $(0.2 \mathrm{mM})$ labeled FISHNanoSIMS was completed according to Burow et al. (2012) and consisted of 10 hour overnight incubations in microcosm vials. Unlabeled mat sections, paraformaldehyde (PFA) fixed mat cores, and continuously dark microcosms served as controls. Mat cores were washed twice in label free media and immediately flash frozen at $-80^{\circ} \mathrm{C}$ prior to FISH and NanoSIMS analyses. Bulk isotope ratios for ${ }^{13} \mathrm{C} /{ }^{12} \mathrm{C}$ (reported as $\delta^{13} \mathrm{C}$ in permil relative to VPDB) were determined by IRMS (ANCAIRMS; PDZ Europa Limited, Crewe, England) at the University of California, Berkeley, with IAEA and NIST peach leaf standards used for $\mathrm{C}$ isotope standard corrections (Woebken et al., 2012). For each mat type, IRMS measurements were analyzed for significant differences using Student's $t$-test between different trials.

\section{FISH and NanoSIMS}

As previously described, CARD-FISH was used to hybridize fluorescent oligonucleotides to cells of Chloroflexi (CFX1223 and GNSB-941) (Woebken et al., 2012; Burow et al., 2013) and Desulfosarcina / Desulfobacteraceae (DSS658) (Burow et al., in press). M. chthonoplastes bundles were directly identified by morphology using scanning electron microscopy (SEM) on a FEI Inspect F (Hillsboro, Oregon, USA). Using the FISH, Chlorophyll $a$ autofluorescence, and SEM micrographs as a guide to the location of specific cells types, high-resolution secondary ion mass spectrometry (SIMS) was performed at Lawrence Livermore National Laboratory with a Cameca NanoSIMS 50 (Gennevilliers, France). NanoSIMS data were analyzed for normal distribution with the Student's $t$-test and Shapiro-Wilk W test, and in cases where the data did not meet the standard $(p<0.05)$ of normality, the Wilcoxon (Whitney-Mann) test was used to confirm the initial result of significant differences using Student's $t$-test. Statistical tests were computed in $\mathrm{R}$ (2.15.1) (Ihaka and Gentleman, 1996). The ${ }^{13} \mathrm{C} /{ }^{12} \mathrm{C}$ ratio was measured using ${ }^{12} \mathrm{C}_{2}$ and ${ }^{13} \mathrm{C} /{ }^{12} \mathrm{C}$ corrected for the dimer abundances and converted to permil enrichment (Pett-Ridge and Weber, 2012). Measurements were made in both imaging and spot analysis modes. Uptake of the respective ${ }^{13} \mathrm{C}$-labeled compound was determined based on ${ }^{13} \mathrm{C}$ enrichment relative to unlabeled, PFA fixed samples as a reference.

\section{RESULTS}

\section{PYROTAG ASSAY RESULTS OF GN-I AND GN-S MATS}

16S SSU rRNA gene pyrotag libraries provide a way to survey a large fraction of a microbial community to determine community composition and population statistics, as well as to track population changes between samples (Hamady et al., 
2008; Kuczynski et al., 2010). Table 1 shows the estimated OTU richness and sequencing depth of the samples collected at 1200 and 2400 over the same diel cycle. DNA libraries were much more diverse than cDNA libraries and indicated that a small number of clades were responsible for a large fraction of the ribosomal expression in mats. Overall, coverage based on Chaol and ACE estimators was approximately half in samples, though the proper usage of alpha diversity estimators in high-throughput sequencing studies (combined with denoising or clustering) is still debated (Reeder and Knight, 2010; Gihring et al., 2012) and therefore should be interpreted as a preliminary measure of coverage. Assuming that dominant organisms received adequate sequencing coverage, only OTU expression ratios (cDNA: DNA) of genera $>1 \%$ in DNA libraries were examined during downstream analysis and only the top genera in phyla were highlighted. In Figure 1A, phylum level results of pyrotag libraries showed Proteobacteria, Cyanobacteria, and Chloroflexi dominate the DNA libraries, with relatively lower levels of Bacteroidetes than in previously sequenced GN-S samples (Ley et al., 2006). In GN-S mats, the OTUs from the genus Microcoleus had the highest expression ratio, and in GN-I mats, OTUs from the genus Lyngbya (followed by Microcoleus) had the highest expression ratio. While overall Alphaproteobacteria community composition was similar between the two GN mat types (Figure 1B), (primarily diazotrophic and purple non-sulfur (PNS) bacteria, Online Information, Krona pie charts), there were generally more Alphaproteobacteria sequences in GN-I samples than in GN-S samples. Additionally, Proteobacteria represented the largest fraction of the community, with major mat functional groups (Fenchel and Finlay, 1995) represented (i.e., PNS in Alphaproteobacteria, SRBs in Deltaproteobacteria, sulfur-oxidizing bacteria in Gammaproteobacteria) (Online Information). The third-most abundant phyla in the mats, Chloroflexi (Figure 1C), was divided between the phototrophic (class Chloroflexi) and the dark filamentous clades of the Anaerolineae and

Table 1 | OTU richness and sampling depth of pyrotag samples from GN-S and GN-I mats.

\begin{tabular}{lccl}
\hline Library & \multicolumn{3}{c}{ OTU richness } \\
\cline { 2 - 3 } & $\begin{array}{c}\text { Observed } \\
\text { species }\end{array}$ & \multicolumn{1}{c}{ Chao1 } & \multicolumn{1}{c}{ ACE } \\
\cline { 2 - 3 } & & Avg. (SD) & Avg. (SD) \\
\hline GN-S 1200 DNA & 3042 & $5252(49)$ & $5743(41)$ \\
GN-S 1200 cDNA & 1944 & $3818(179)$ & $4124(154)$ \\
GN-S 2400 DNA & 3326 & $6068(137)$ & $6766(123)$ \\
GN-S 2400 cDNA & 1243 & $2322(121)$ & $2511(97)$ \\
GN-I 1200 DNA & 3417 & $6747(180)$ & $7465(189)$ \\
GN-I 1200 cDNA & 1404 & $2511(105)$ & $2643(88)$ \\
GN-I 2400 DNA & 3559 & $6679(124)$ & $7285(120)$ \\
GN-I 2400 cDNA & 1545 & $2840(128)$ & $3016(107)$
\end{tabular}

Average population statistics are shown with standard deviations of subsample distributions ( $n=100,11,500$ sequences) in parentheses. Observed Species statistics were computed at the full sampling depth.

Caldilineae. The most abundant identifiable genus level OTUs from phylum Chloroflexi matched reference sequences for the filamentous anoxygenic phototrophic Oscillochloris (and the Oscillochloridaceae generally, Online Information).

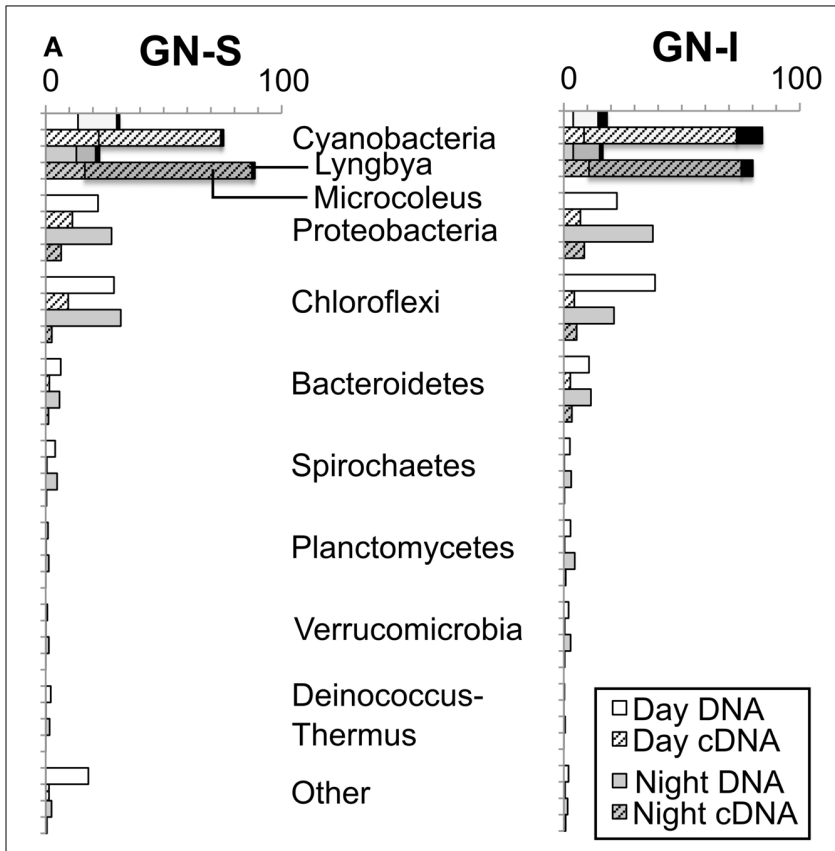

B

GN-S

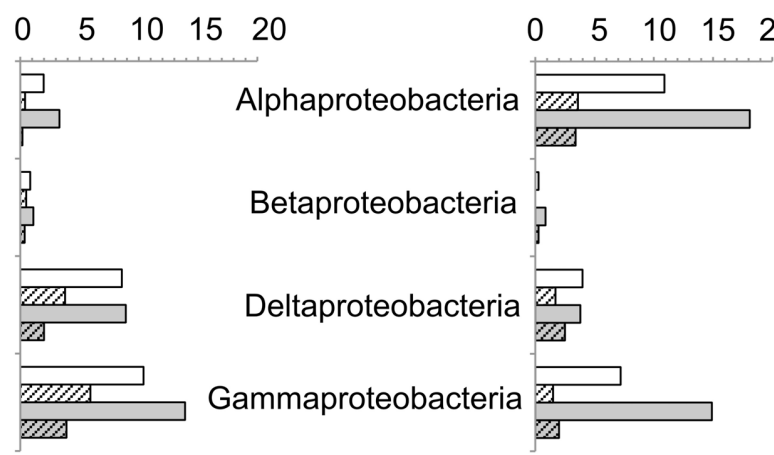

C

GN-S

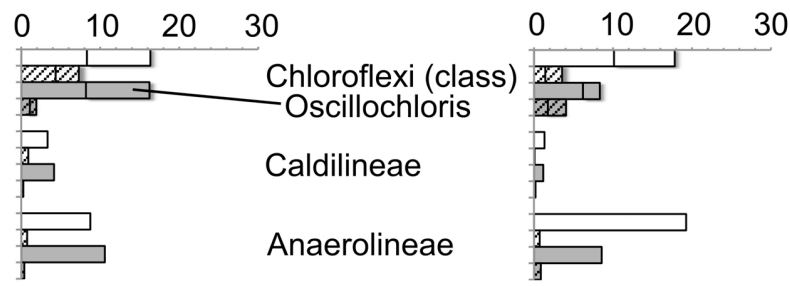

FIGURE 1 | Relative abundance of pyrotag sequences of intertidal (GN-I) and submerged (GN-S) microbial mats from Guerrero Negro, B.C.S., Mexico. (A) Phylum level overview showing most abundant and most active OTUs [Microcoleus (shadowed), Lyngbya (black)]; (B) abundance within Proteobacteria; and (C) abundance within Chloroflexi with shadowing for Oscillochloris. 


\section{MICROCOSM STUDIES OF THE IMPACT OF NITROGEN FIXATION AND OXYGENIC PHOTOSYNTHESIS ON FERMENTATION}

To determine whether similar processes and ecology account for the chemical cycling observed in Guerrero Negro mats as in Elkhorn Slough mats, both GN-S and GN-I mats were subjected to microcosm-based studies. Experiments were conducted on cores of harvested mat cut down to the top $2 \mathrm{~mm}$ and placed in microcosm vials with site water and sealed. Reduced gases and fermentation products were collected at periodic intervals over the diel. Hydrogen gas and organic acids were produced only during the dark portion of the diel cycle with more of each produced in GN-I mats (Figure 2), with the relative abundance of organic acids consistently corresponding to: acetate $>$ formate $>$ propionate (Figure 2B). Additionally, two separate manipulation experiments were conducted to differentiate the influence of nitrogen fixation and oxygenic photosynthesis on nighttime fermentation. Ammonium chloride manipulations were intended to suppress the effect of nitrogenase and nitrogen fixation to examine the impact on fermentation rates. No significant difference was observed on net hydrogen and organic acid production between control and nitrogen replete treatments (Figures 2A,B), with the exception of a reduction in net formate production in
GN-I mats. This is consistent with previous work conducted on Elkhorn Slough mats that showed that hydrogen production at night was largely uninfluenced by nitrogen fixation and constitutive fermentation was the main contribution to hydrogen production (Burow et al., 2012).

In the second experiment, DCMU (which inhibits photosystem II found in Cyanobacteria) was added in an effort to help clarify the role of oxygenic photosynthesis on fermentation activity in these mats. Inhibition was verified by oxygen microelectrode profiles showing anoxic conditions within $200 \mu \mathrm{m}$ of the mat water interface (data not shown). Net hydrogen production was significantly lower in DCMU treated mats (Figure 2C), while net acetic acid production was higher (Figure 2D). This was the only manipulation experiment in which hydrogen and net organic acid production did not change in concert in a microcosm. Figure 3 shows isotopic enrichment following ${ }^{13} \mathrm{C}$-bicarbonate labeling of GN mats exposed to DCMU and light. In both mat types, the ${ }^{13} \mathrm{C}$ enrichment of DCMU-exposed mats resembled that of control mats incubated in the dark rather than light, suggesting that mats were not fixing carbon during the day. These observations are consistent with past studies that used DCMU to switch mats into an anoxic, nitrogen-fixing, sulfate-reducing
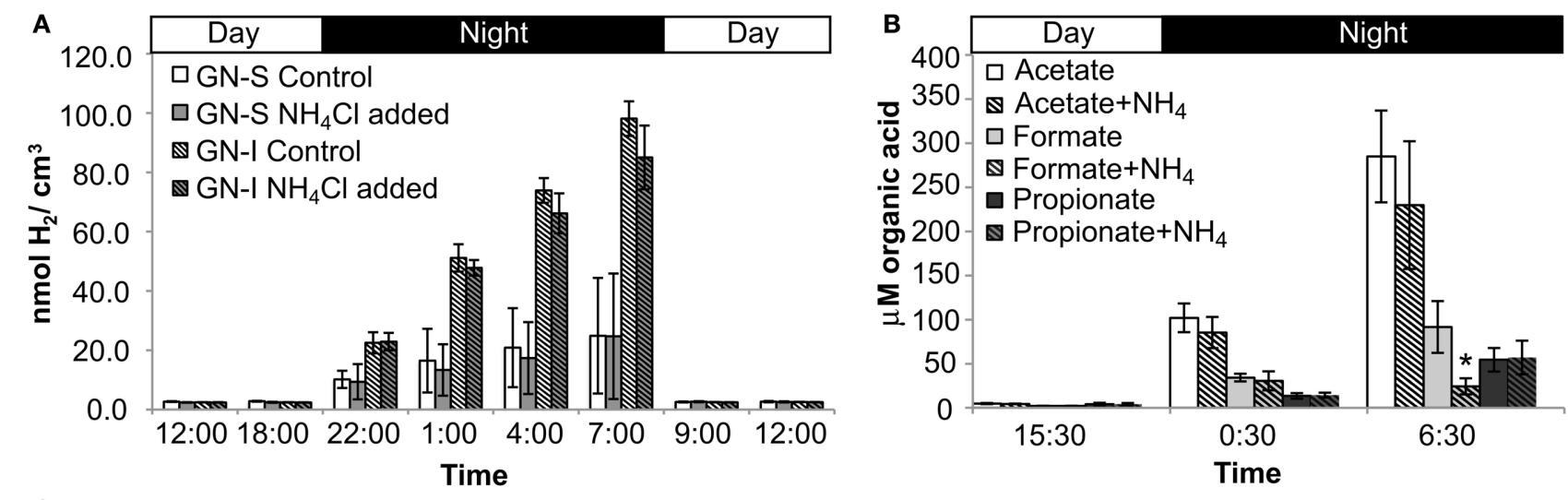

C

D
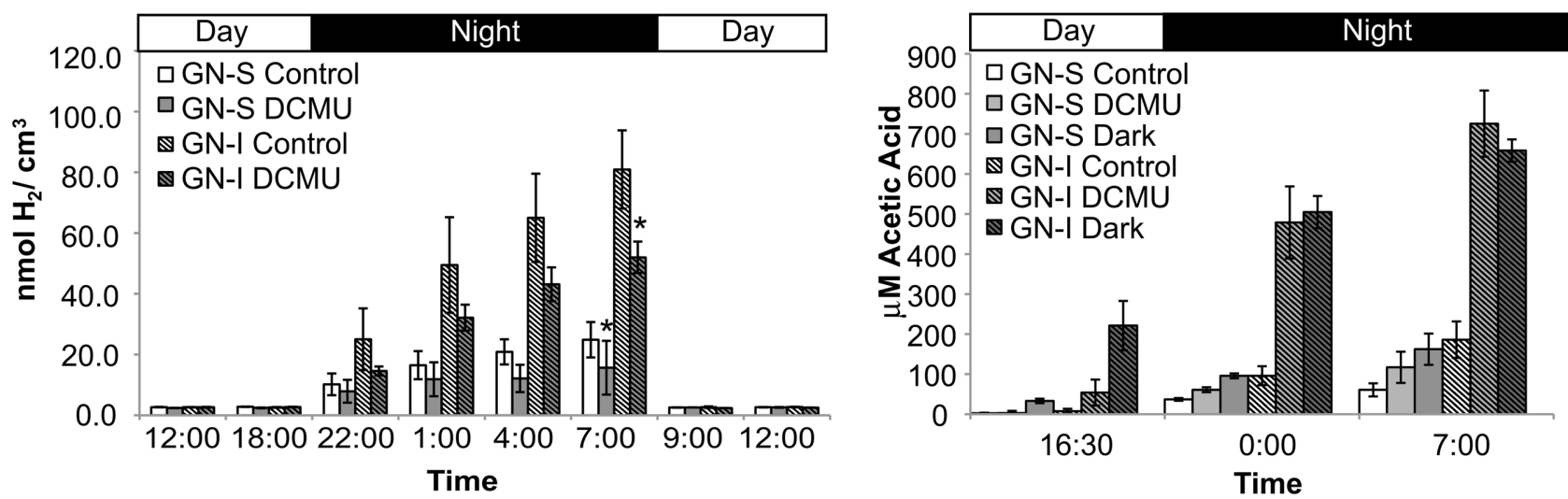

FIGURE 2 | Hydrogen and organic acid production in diel manipulation experiments with two microbial mats types from Guerrero Negro, B.C.S., Mexico. $\mathrm{NH}_{4} \mathrm{Cl}$ manipulation (inhibition of nitrogen fixation): (A) $\mathrm{H}_{2}$ production (B) net organic acid production
(GN-I only). DCMU manipulation (photosynthesis inhibition via photosystem II disruption): (C) $\mathrm{H}_{2}$ production and (D) net acetic acid production. Error bars indicate standard deviation of 6 replicate trials. Asterisk indicates $p<0.05$ to control case by Student's $t$-test. 
mode during daylight (Bebout et al., 1987, 1993; Steppe and Paerl, 2002). We further verified our findings by measuring daytime ${ }^{13} \mathrm{C}$-bicarbonate uptake in individual Microcoleus morphotype filaments by NanoSIMS isotopic imaging (Figure 4). Control filaments incorporated significantly more labeled bicarbonate relative to DCMU-exposed filaments during daylight.

\section{IDENTIFYING MAJOR HYDROGEN PRODUCERS AND CONSUMERS IN MATS BY HYDROGENASE (HoxH) PHYLOGENY}

To identify the organisms responsible for the production and consumption of hydrogen in Guerrero Negro mats, 117 transcripts

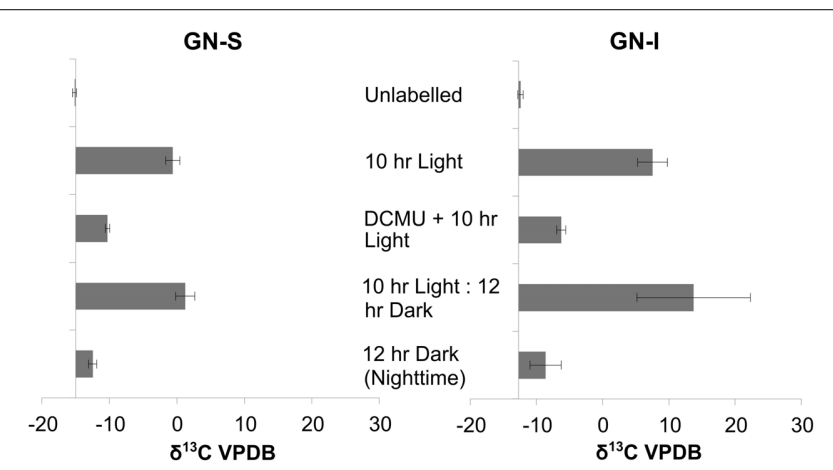

FIGURE 3 | Isotopic enrichment (measured by IRMS) of GN-S and GN-I mats following ${ }^{13} \mathrm{CHO}_{3}$ - labeling and DCMU inhibition of photosystem II and photoautotrophy. Samples were collected after either $10 \mathrm{~h}$ of lighted label exposure, $10 \mathrm{~h}$ of light plus $12 \mathrm{~h}$ of darkness, or $12 \mathrm{~h}$ of darkness. Error bars are standard deviation of 4 replicate trials.

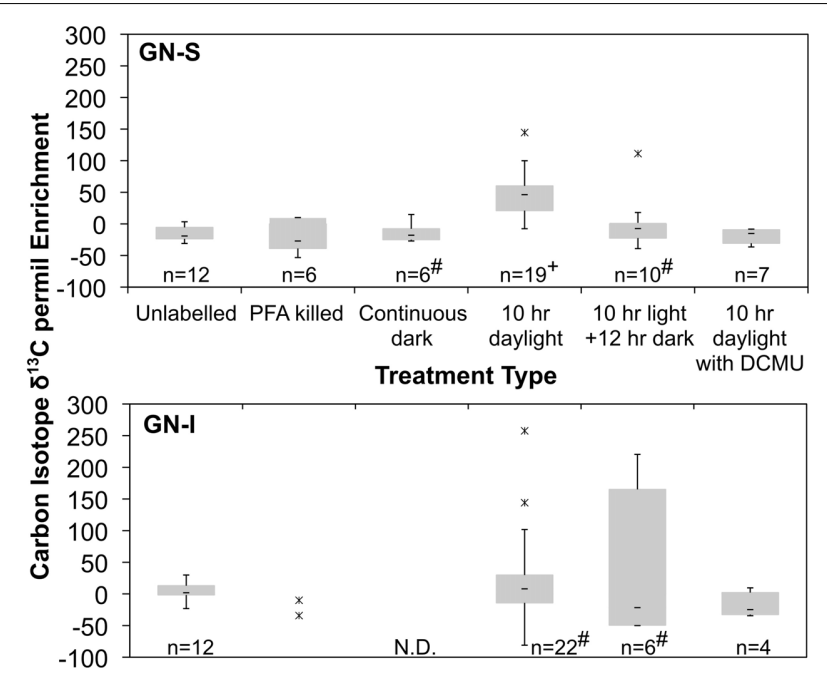

FIGURE 4 | Quartile box plots of NanoSIMS isotope ratio measurements of Microcoleus morphotype filaments labeled with ${ }^{13} \mathrm{C}$-bicarbonate for trials of unlabeled, PFA killed, continuous dark, $10 \mathrm{~h}$ daylight, $10 \mathrm{~h}$ daylight followed by $12 \mathrm{~h}$ night, and $10 \mathrm{~h}$ daylight with DCMU added. Data was collected via multiple spot measurements of multiple filaments for each mat type (GN-S, at top; GN-I, at bottom). Asterisks are outlier datapoints identified as 1.5*IQR (Inter Quartile Range) outside quartiles. Outliers were retained in analysis. "\#" denotes distributions for which the Shapiro-Wilk test $p<0.05$. " + " denotes significantly different to all other GN-S trials (Wilcoxon test, $p<0.05)$. "N.D." denotes no data taken. (in 17 OTUs) of [NiFe]-hydrogenases of type $3 b$ were sequenced and passed quality control. Figure 5 shows the phylogenetic relationship of OTUs detected from GN-I and GN-S mats. In both mat types, the majority of the observed hydrogenases were from Cyanobacteria of both filamentous and unicellular types. In GNI mats, transcript OTUs related to Lyngbya sp. PCC 8106 were seen to be most abundant, and additional OTUs of mat-associated filamentous Cyanobacteria such as Microcoleus chthonoplastes PCC 7420 were also seen. In GN-S mats, the most abundant OTUs came from an unknown cyanobacterium in Oscillatoriales or Pleurocapsales whose closest BLAST match ( 94\% ID by BLASTp) was Pleurocapsa sp. PCC 7319. Transcripts related to Microcoleus chthonoplastes PCC 7420 were detected as well. The remaining hydrogenases observed in these mats were most related to clusters of hydrogenases previously reported in Elkhorn Slough mats (Burow et al., 2012). Therefore, the distribution of abundant hydrogenases in hypersaline microbial mats appears to fit a pattern of cyanobacterial clusters, with additional diverse unidentified groupings of lower abundances. Notably, no sequences for hydrogenases from the anoxygenic phototrophs of the Chloroflexi were detected.

\section{ACCUMULATION OF FIXED CARBON AND RELEASE OF FERMENTATION BYPRODUCTS IN MICROCOSM STUDIES}

The presence of fermentation products in Guerrero Negro mat types, though detectable, may not be in meaningful quantity to influence the overall cycling of carbon in the ecosystem. Therefore, several experiments were completed to measure the relative magnitude of fixed carbon in relation to fermentation products released in GN-I mats. Changes in concentration of DIC in the water overlying incubated mats were taken to reflect total flux of carbon due to fixation or respiration (Figure 6). The observed flux was into the mats (negative) primarily during the daylight period and into the water column (positive) primarily during the nighttime period, consistent with previous work (Des Marais, 1995). Glycogen measurements from mat cores at different times were used to estimate the amount of stored fixed carbon in mats across the diel. Both mat types did exhibit a daytime accumulation (net gain) and nighttime loss (net loss) of glycogen, though the absolute magnitude of glycogen was 2.5-fold higher in GN-S mats than in GN-I mats while the net diel change differed by only $25 \%$ (higher in the GN-S mat) (Figure 7).

To relate these different fluxes and pools to each other, and to the fermentation results from the microcosm studies, an electron mass balance was constructed (Table 2) (See Section Photosynthesis/Fermentation Mass and Electron Balance for methods and conditions used). DIC and glycogen fluxes over the day and night period were averaged to determine a single flux over the diel. For organic acids and hydrogen, both "net" and "total" values are given. "Net" values were derived from fluxes observed under control conditions, and were assumed to incorporate the effects of $\mathrm{H}_{2}$ consumption by spatially-associated accessory populations as well as $\mathrm{H}_{2}$ production in whole intact mats. "Total" values were derived from fluxes observed when mats were homogenized to disrupt physical associations and thereby decrease or eliminate consumption by accessory organisms. Under these conditions, the flux of hydrogen, acetate, and propionate roughly 


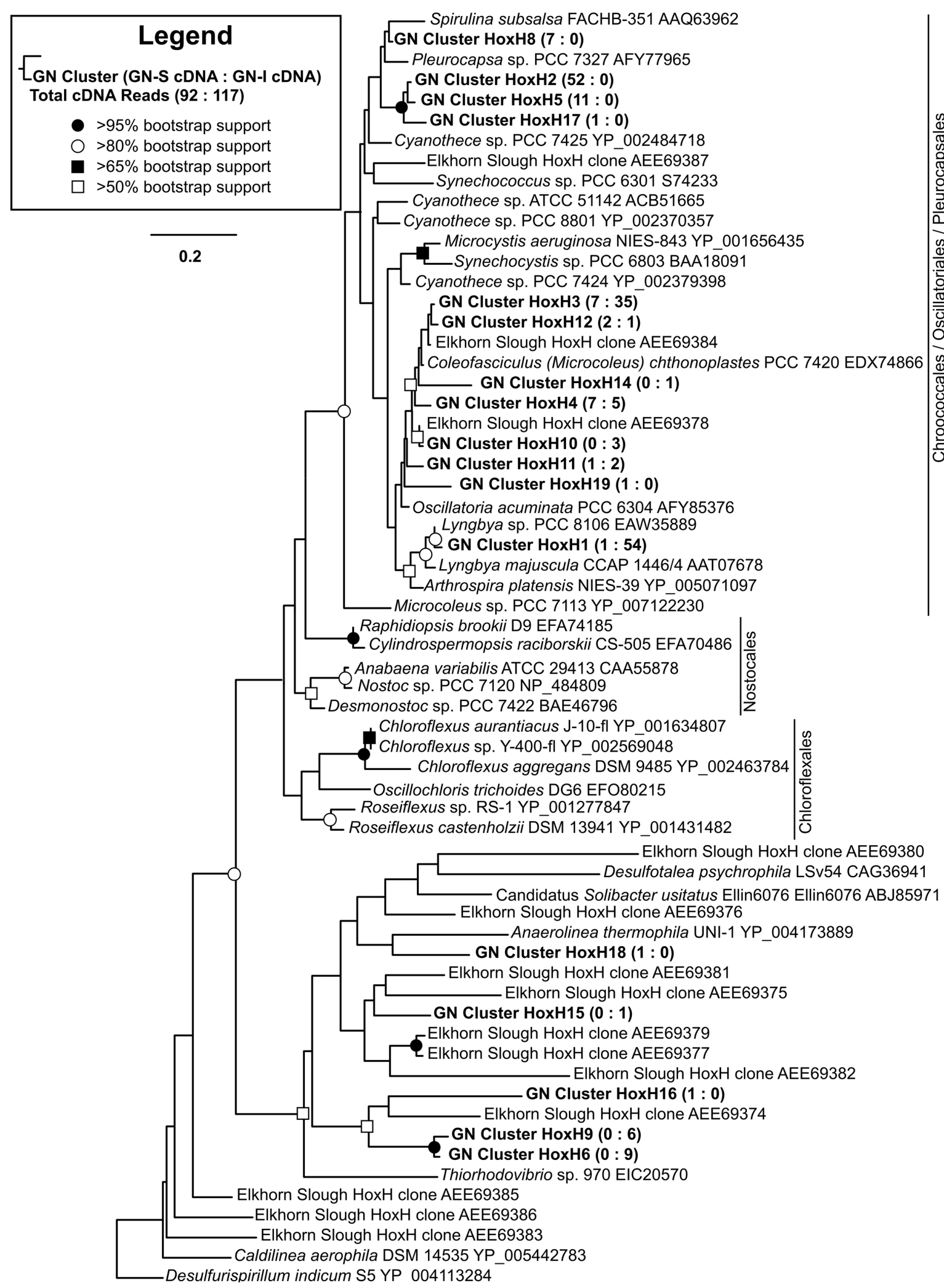

FIGURE 5 | Phylogenetic relationship of type $\mathbf{3 b}$ [NiFe]-hydrogenases detected from GN-I and GN-S mats. Maximum likelihood (ML) phylogram inferred from partial hoxH transcript sequence data for selected taxa, with an emphasis on the Cyanobacteria and Chloroflexi. Symbols denoting bootstrap support values are for both $\mathrm{ML}$ and neighbor joining analyses. Representative sequences for OTUs identified from this study are in bold. Numbers in parentheses after study sequences denote number of sequences for each OTU from GN-S mats (left), and GN-I mats (right). 


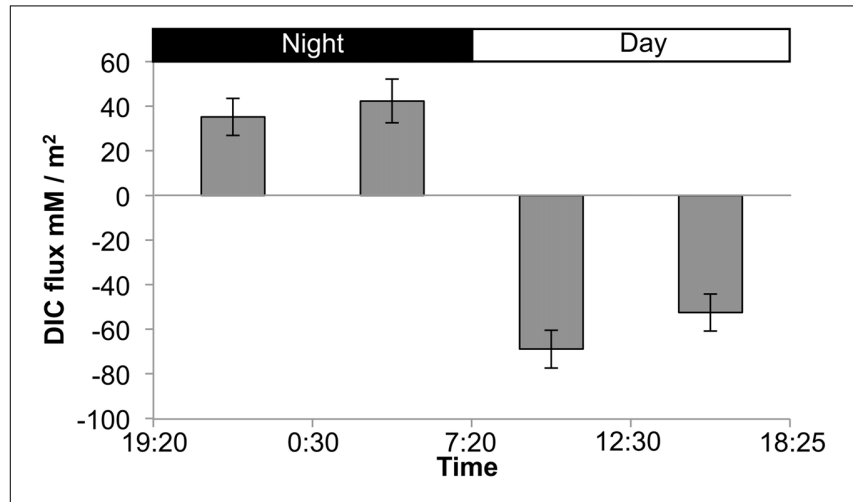

FIGURE 6 | Flux chamber measurements of dissolved inorganic carbon (DIC) flux from GN-I mats over a diel period. Values reflect net flux of DIC between the indicated times. Error bars are standard deviations of 4 replicate trials.

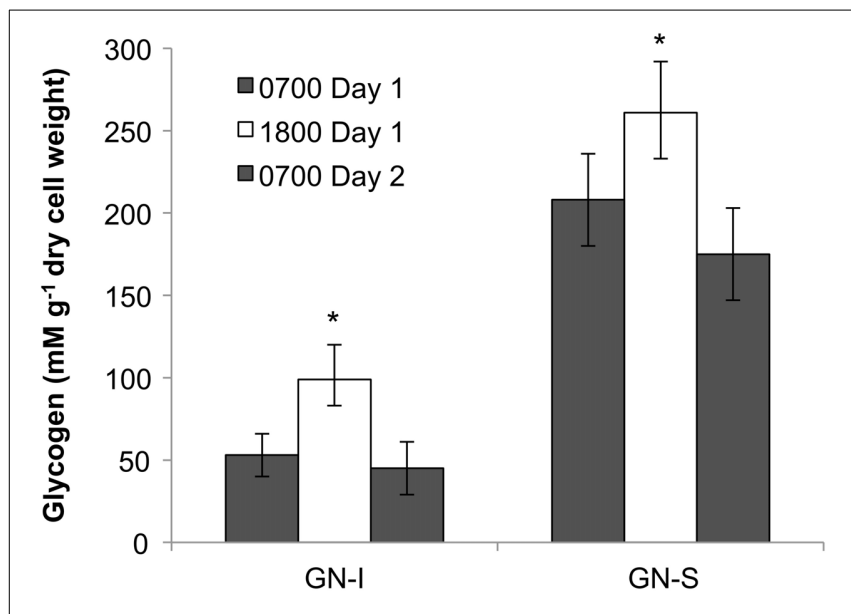

FIGURE 7 | Glycogen accumulation over the diel cycle in GN-I and GN-S mats over the diel. Error bars represent standard deviation of 9 replicate cores per time point. Asterisk indicates $p<0.05$ by unpaired 2-tailed Student's $t$-test to both 0700 sample sets.

doubled over controls. Because it is not certain that disruption completely eliminates consumption of fermentation products, this "total" value should be taken as a lower bound on the maximum possible production of fermentation products. Approximately $81 \%$ of the photosynthetically fixed electrons are released as total fermentation products during the night. Based on the differing "net" and "total" fluxes of fermentation products, it appears that about $41 \%$ of net photosynthetic carbon fixation was ultimately consumed by accessory populations within the mat. Quantitatively, hydrogen was a minor contributor to the overall cycling of photosynthetically-fixed electrons in these mats. The majority was accounted for as organic acids, specifically as acetate.

\section{MICROCOSM STUDIES OF HYDROGEN CONSUMPTION IN MICROBIAL MATS}

Similar to the microcosms used to test nitrogen fixation and oxygenic photosynthesis in hydrogen production, a combination of experimental microcosms were used to characterize and quantify microbial hydrogen consumption. Sulfate deprivation and molybdate addition were intended to reduce the activity of sulfate reduction, and were conducted both individually and together in microcosms. Disruption was intended to physically separate mat community members and was conducted in a separate microcosm experiment. Both sulfate deprivation alone, and sulfate deprivation with molybdate addition resulted in significantly diminished accumulation of hydrogen sulfide (the end product of sulfate reduction) within microcosm vials, but with the second case having a much larger effect (Figure 8A). In GN-I mats, net hydrogen production was enhanced by both disruption and molybdate addition with sulfate deprivation (Figure 8B), while hydrogen production in GN-S mats was enhanced only by sulfate deprivation with molybdate inhibition (Figure 8D). Because our method for quantifying organic acids is not compatible with molybdate, we could only examine the effect of physical disruption on organic acid production, which showed that production of acetate and propionate roughly double in GN-I mats due to physical disruption (Figure 8C).

\section{ORGANIC ACID UPTAKE IN MICROBIAL MATS}

Organic acids produced by nighttime fermentation have the potential to serve as substrates for both sulfate reduction and photoheterotrophy. The former was suggested by the significant enhancement of nighttime organic acid production upon physical disruption (Figure 8C). Photoheterotrophy was suggested in Elkhorn Slough mats by Burow et al. (2013) to be related to the activity of Chloroflexi. To further characterize and quantify organic acid uptake, mats from both GN and Elkhorn Slough were incubated overnight with ${ }^{13} \mathrm{C}$-labeled acetate, and analyzed for isotopic enrichment by NanoSIMS. The final amended ${ }^{13} \mathrm{C}$-acetate concentration $(0.2 \mathrm{mM})$ was not greater than maximum values of accumulation in mats and represented similar concentrations in natural unamended mats. Probes specifically for phylum Chloroflexi (CFX1223 and GNSB-941) and for Desulfobacteraceae (DSS658) were used to determine if hybridized cells took up acetate. Figure 9 shows NanoSIMS measurements of hybridized filaments for three mat types compared to microbial filaments with no hybridization. Figures 9A-D show paired Chlorophyll $a$ autofluorescence (A), Chloroflexi probe CARDFISH (B), and NanoSIMS ${ }^{13} \mathrm{C}$ enrichment (C), and NanoSIMS secondary electron images (D). Figures $\mathbf{9 E}-\mathbf{H}$ shows a similar set of paired images for the Desulfobacteraceae probe. Figure 9I shows a quartile box plot summarizing NanoSIMS isotopic spot measurements over a number of different mat types and across replicate samples and the significance of the distribution when compared to filaments that did not hybridize with probes. All three mat types showed enrichment in CFX1223/GNSB-941 hybridized cells by NanoSIMS imagery and spot measurements, but varying patterns of enrichment between filaments within samples was observed. DSS658 hybridized filaments also showed enrichment, but generally much less than for CFX1223/GNSB941 filaments. In GN-I mats, no DSS658 hybridization was visible in microscopy. In all cases, significant enrichment was observed over unhybridized filaments, but enrichment in Chloroflexi 
Table 2 | Fermentation product concentration and equivalent electron balance in GN-I mat microcosms showing the amount of light captured electrons in fixed carbon analytes (during the day) and in fermentation by-products (produced at night).

\begin{tabular}{|c|c|c|c|c|c|}
\hline & $\begin{array}{c}\text { Daytime } \\
\text { flux/storage }\end{array}$ & $\begin{array}{l}\text { Nighttime } \\
\text { flux/storage }\end{array}$ & $\begin{array}{c}\text { Avg. diel } \\
\text { flux/storage }\end{array}$ & $\mathrm{e}^{-}$equivalents & $\begin{array}{l}e^{-} \text {flux/ } \\
\text { storage }\end{array}$ \\
\hline & $\mathrm{mmol} / \mathrm{m}^{2}$ & $\mathrm{mmol} / \mathrm{m}^{2}$ & $\mathrm{mmol} / \mathrm{m}^{2}$ & & $\mathbf{m m o l ~} \mathrm{e}^{-/ \mathrm{m}^{2}}$ \\
\hline Fixed inorganic- $\mathrm{C}\left(\mathrm{CH}_{2} \mathrm{O}\right)$ & $-121.4(10.3)$ & $77.5(6.9)$ & $99.5(8.6)$ & 4 & 397.9(34.4) \\
\hline Glycogen & $21.2(25.2)$ & $-31.6(30.4)$ & $26.4(27.8)$ & 24 & $633.8(667.2)$ \\
\hline Formate & - & $8.3(1.2)$ & $8.3(1.2)$ & 1 & $8.3(1.2)$ \\
\hline Propionate & - & $2.4(0.5)$ & $2.4(0.5)$ & 13 & $31.7(6.1)$ \\
\hline $\mathrm{H}_{2}$ & - & $0.83(0.05)$ & $0.83(0.05)$ & 2 & $1.66(0.09)$ \\
\hline \multicolumn{6}{|l|}{ TOTAL FERMENTATION } \\
\hline Acetate & - & $28.0(1.3)$ & $28.0(1.3)$ & 8 & $224.2(10.1)$ \\
\hline$\%$ Fixed $e^{-}$fermented & & & & & $81.2(14.6)$ \\
\hline$\%$ Fixed $e^{-}$taken up by accessory microbes & & & & & $40.8(14.0)$ \\
\hline
\end{tabular}

Values were normalized to microcosm mat diel flux or storage rate and core cross-sectional area, mmol/ $\mathrm{m}^{2}$. Net fermentation by-product measurements were from control microcosms, and total fermentation byproducts were from homogenized microcosms.

and Desulfobacteraceae was notably higher in Elkhorn Slough samples.

\section{SURVEYING THE DIVERSITY OF SULFATE REDUCING BACTERIA THROUGH DsrA PHYLOGENY IN GUERRERO NEGRO MATS}

DsrA phylogeny of sequences derived from both mat types are shown in Figure 10. Nodes of the family Desulfobacteraceae did not generally bootstrap well, but genera of the family Desulfobacteraceae formed a monophyletic clade, as did genera within the family Desulfobulbaceae. The constructed phylogeny was consistent with the work of Leloup et al. (2009) which showed Desulfovibrionales affiliating with Desulfobulbaceae within Desulfobacterales and also identified both the orthologous and xenologous Desulfotomaculum. In total, 347 cDNA and 105 DNA reads were obtained and binned into 40 OTUs for $d s r A$ genes from the GN-I and GN-S mats. The maximum likelihood analysis for the translated $d s r A$ data in Figure 10 revealed that OTUs were distributed throughout the phylogeny. However, the majority of sequences were clustered into five main groups: two within the Desulfobacteraceae and three within the deeply branching regions of the tree. Though DSS658 labeled cells could not be found in GN-I mats by CARD-FISH, $d s r A$ genes and transcripts belonging to Desulfobacteraceae were detected in both mat types. One main cluster, primarily from the GN-I mats, formed a well-supported clade with a DsrA sequence identified from the intertidal mats found at Elkhorn Slough, CA, USA (accession JX502749, Burow et al., in press), this may represent a novel "intertidal" lineage of Desulfobacteraceae. A second cluster did not affiliate closely with any described SRB taxa, and was not supported by bootstrap analysis, but was placed within the Desulfobacteraceae. This grouping was particularly high in transcript content (197 cDNA reads vs. only 6 DNA reads) and distributed in both GN-I and GN-S environments. Finally, several OTUs grouped deep in the tree together in what Harrison et al. (2009) refers to as the "deep-branching dsrA." These OTUs tended to cluster with other cloned sequences from studies of sediments and marshes (Castro et al., 2002; Bahr et al., 2005) and have an as yet unknown role in these mats. No naming convention for clades was apparent in the numerous published DsrA phylogenies, but these deep OTUs affiliated with sequences belonging to what have been previously termed clade IV (Dhillon et al., 2003; Bahr et al., 2005; Zhang et al., 2008), clade V (Kaneko et al., 2007; Zhang et al., 2008; Harrison et al., 2009), and/or clade DSR-2 (Castro et al., 2002) and at least one clade may contain members derived from horizontal gene transfer (Mussmann et al., 2005). Of the deeply-branching clades, one deeply branching group contained an abundant OTU from GN-S, one contained an abundant OTU from GN-I, and the last contained rare OTUs from GN-I mats.

\section{DISCUSSION}

Previous work (Skyring et al., 1989; Burow et al., 2012) suggested that nighttime production of reduced gases results from photoautotrophy and storage of reduced carbon by Cyanobacteria with subsequent fermentation of stored photosynthate following the onset of dark, anoxic conditions (Hoehler et al., 2001; Des Marais, 2003). In Elkhorn Slough mats, Cyanobacteria were indicated as the dominant fermenter (Burow et al., 2012) and sulfate reducers as a key consumer of $\mathrm{H}_{2}$ (Burow et al., in press). This study builds on previous reports of $\mathrm{H}_{2}$ cycling in microbial mats in three important regards. First, bulk chemical cycling and the underlying ecology are shown to be common 

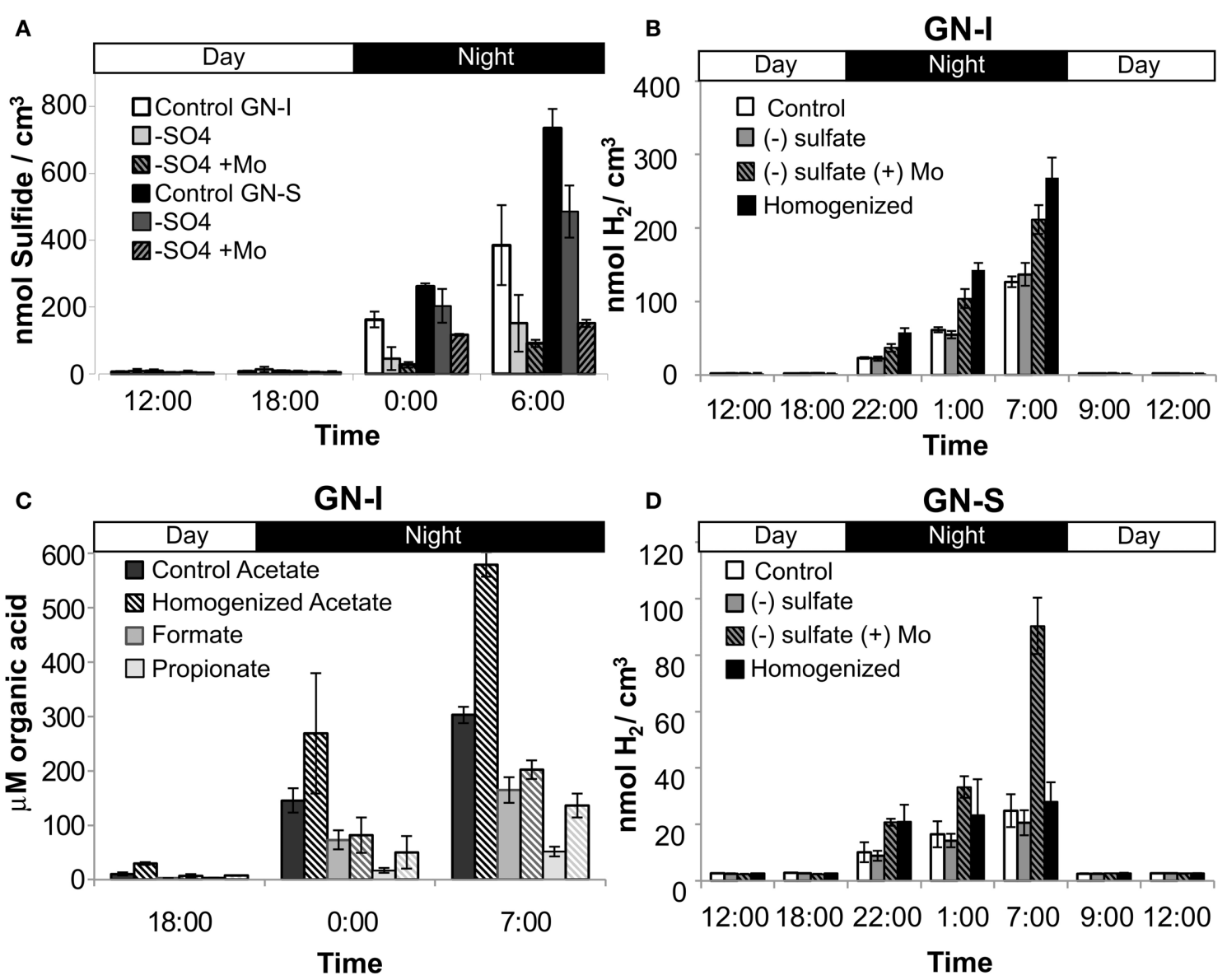

FIGURE 8 | Hydrogen consumption and SRB activity in two microbial mat types from Guerrero Negro, B.C.S., Mexico. Net hydrogen sulfide production (both mats) (A), net hydrogen production in $\mathrm{GN}-\mathrm{I}$ mats (B), net organic acid production in $\mathrm{GN}-\mathrm{I}$

mats (C), and net hydrogen production in GN-S mats (D), showing the effect of physical disruption, sulfate deprivation, and molybdate addition on microcosms. Error bars indicate standard deviation of 6 replicate trials.

features of geographically diverse mats, as well as mats constructed by distinctly different Cyanobacteria. Second, organic acid cycling is characterized and quantified, and shown to represent a significant component of overall carbon and electron flow in the studied mats. Last, multiple methods are utilized to demonstrate that exchange of fermentation products serves to directly link Cyanobacteria with sulfate reducers and anoxygenic phototrophs.

\section{FERMENTATION IS OUANTITATIVELY IMPORTANT IN MATS}

If daytime oxygenic photosynthetic fixation of carbon drives the subsequent nighttime fermentation to hydrogen and organic acids, a series of changes in metabolites should be observable as: (1) accumulation during the day and release at night of inorganic carbon based on measurements of the flux of dissolved inorganic carbon (DIC) across the mat-water interface, (2) accumulation during the day and depletion at night of small stored carbon polymers within the mat (e.g., glycogen), and (3) a rise in organic acid flux within the mat at night. These were all observed in the studies presented here. As shown in Table 2 and
Figure 6, inorganic carbon was incorporated into mats during daytime. Figure 7 indicated glycogen as the primary fixed carbon storage molecule in hypersaline microbial mats, with GN-S mats accumulating much more glycogen. Approximately $\sim 81 \%$ of all carbon fixed during the day in GN-I mats was subsequently fermented at night, with most of the net accumulation of fermentation products occurring as organic acids rather than as hydrogen. The small amount of hydrogen released by fermentation activity relative to organic acids was unsuspected given that the hydrogen concentrations in the mat go through a four order of magnitude change in concentration throughout a diel cycle and particularly given that net hydrogen fluxes in GN-I mat are 10 times greater than in the GN-S mat. A stoichiometric fermentation of glucose to acetic acid, carbon dioxide, and hydrogen would produce nearly 2:1 electron ratios of acetate and hydrogen, but the ratios measured in this study were typically closer to 100:1 (Table 2) and suggests that organic acids provide the most quantitatively observable flux of reductant and energy available to the broader community of microbes within the mat under dark/anoxic conditions. 


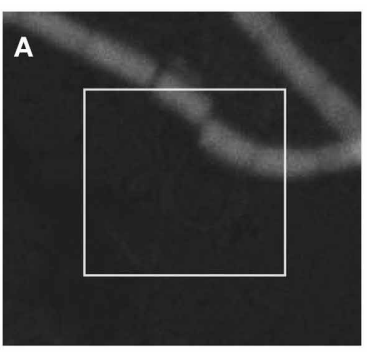

Chl a fluorescence
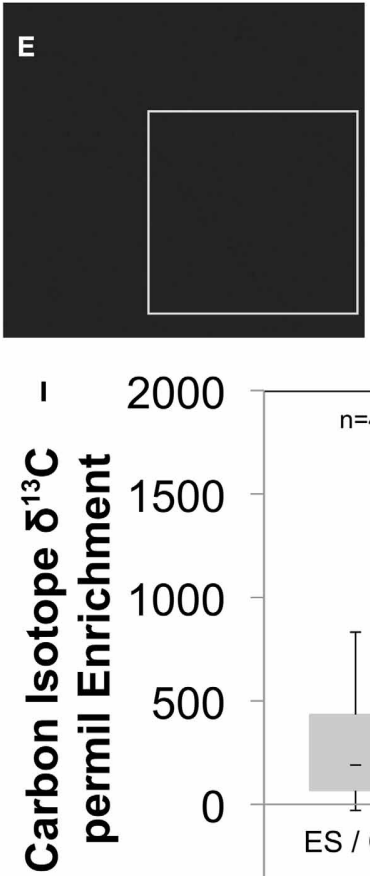

$-500$

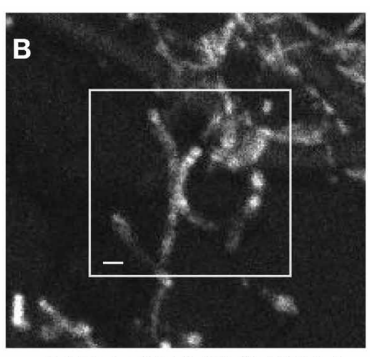

CARD-FISH (CFX1223 / GNSB-941)

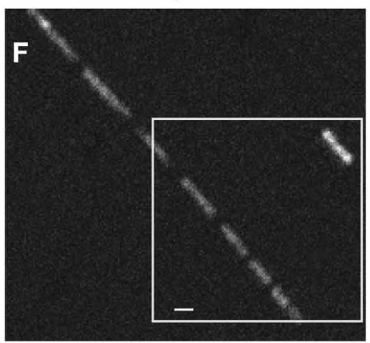

CARD-FISH (DSS658)

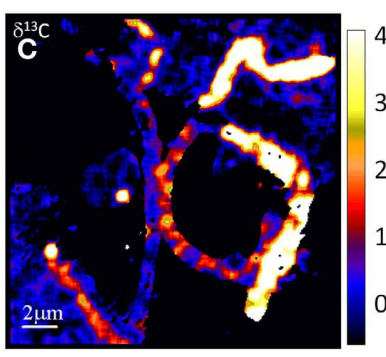

nanoSIMS
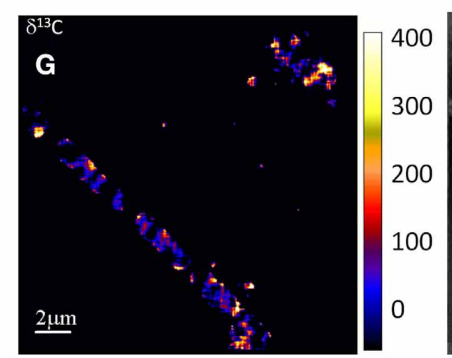

00

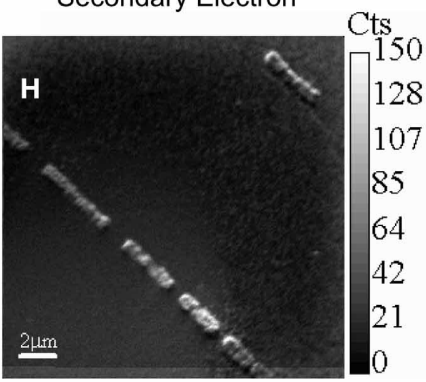

Secondary Electron

N.D.

$n=5$

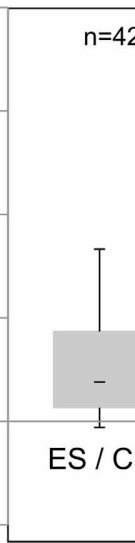

$n=46^{\#}$

$n=24^{\#}$
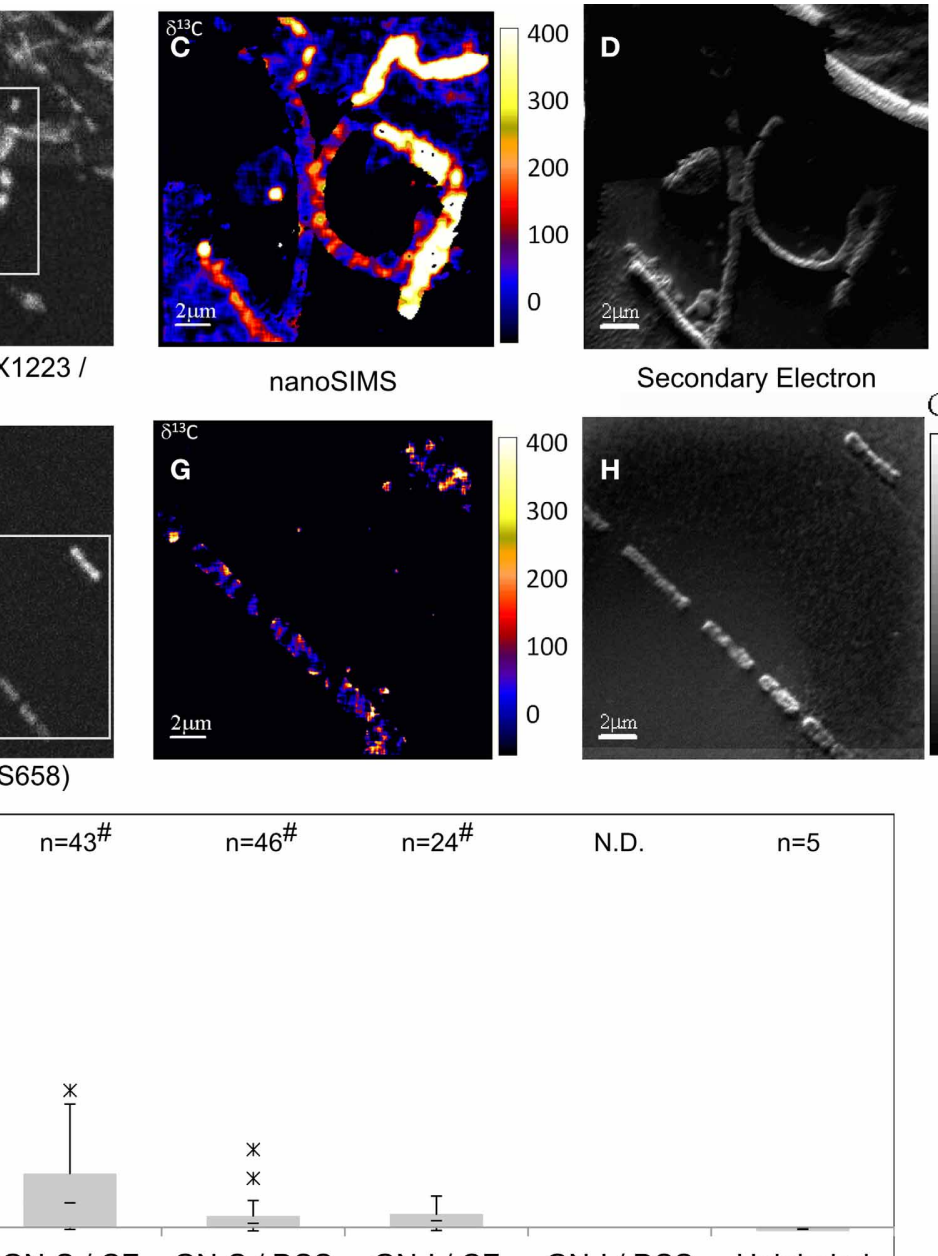

GN-S/CF GN-S/DSS GN-I/CF GN-I/DSS Unlabeled
Mat Type / Probe
FIGURE 9 | Paired Chlorophyll a natural fluorescence, confocal, CARD-FISH, and ${ }^{13} \mathrm{C}$-acetate NanoSIMS (permil) micrographs of GN-S mat (A-H). Chloroflexi (CFX1223 and GNSB-941) (A-D) and

Desulfosarcina/Desulfobacteraceae (DSS658) hybridized filaments (E-H)

shown in conjunction with Chlorophyll a natural fluorescence, CARD-FISH,

${ }^{13} \mathrm{C}$ enrichment, and secondary electron images, respectively. Bar

represents $2 \mu \mathrm{m}$. Quartile box plots of ${ }^{13} \mathrm{C}$-acetate NanoSIMS spot

measurements from Elkhorn Slough (ES), GN-S, and GN-I mats shown in
(I) with significant difference test comparison to isotopic spot

measurements on microbial filaments showing no hybridization to either probe. Asterisk denotes outliers 1.5* IQR outside quartiles (though still kept for analysis). "\#" denotes both Shapiro-Wilk test $p<0.05$ and Wilcoxon difference test $p<0.05$ (compared to unhybridized filaments). "N.D." indicates no hybridized filaments were detected. ES denotes Elkhorn Slough mat samples, CF denotes CFX1223 and GNSB-941 probes, and DSS denotes DSS658 probes.

\section{CONSTITUTIVE FERMENTATION BY CYANOBACTERIA WAS RESPONSIBLE FOR A MAJORITY OF HYDROGEN AND ORGANIC ACID PRODUCTION}

The results of this study indicated similar diel patterns in organic acid and hydrogen production in hypersaline microbial mats from different locations and of different types. Because fermentation of photosynthate represents a loss of reducing power and delivers the lowest energy yield among potential catabolic processes, it could be viewed as a process to be minimized (that is, to be employed only if required by the demands of nighttime metabolism). One potentially large demand for such fermentation would be the energy required to fuel dinitrogen fixation and, for this reason, we examined whether inhibition of dinitrogen fixation (by addition of ammonium as a source of combined nitrogen) diminished the yield of fermentation products. As shown in Figure 2A, and consistent with previous observations in Elkhorn Slough, ammonium addition does not appear to affect fermentation. This suggests that fermentation may be a constitutive aspect of metabolism in these mats, rather than being regulated in response to energetic or other demands of metabolism. The glycogen data and relative ratios of organic acid flux indicate that fermentation of glycogen to acetate was the dominant nighttime pathway, with a smaller component of mixed acid fermentation. 


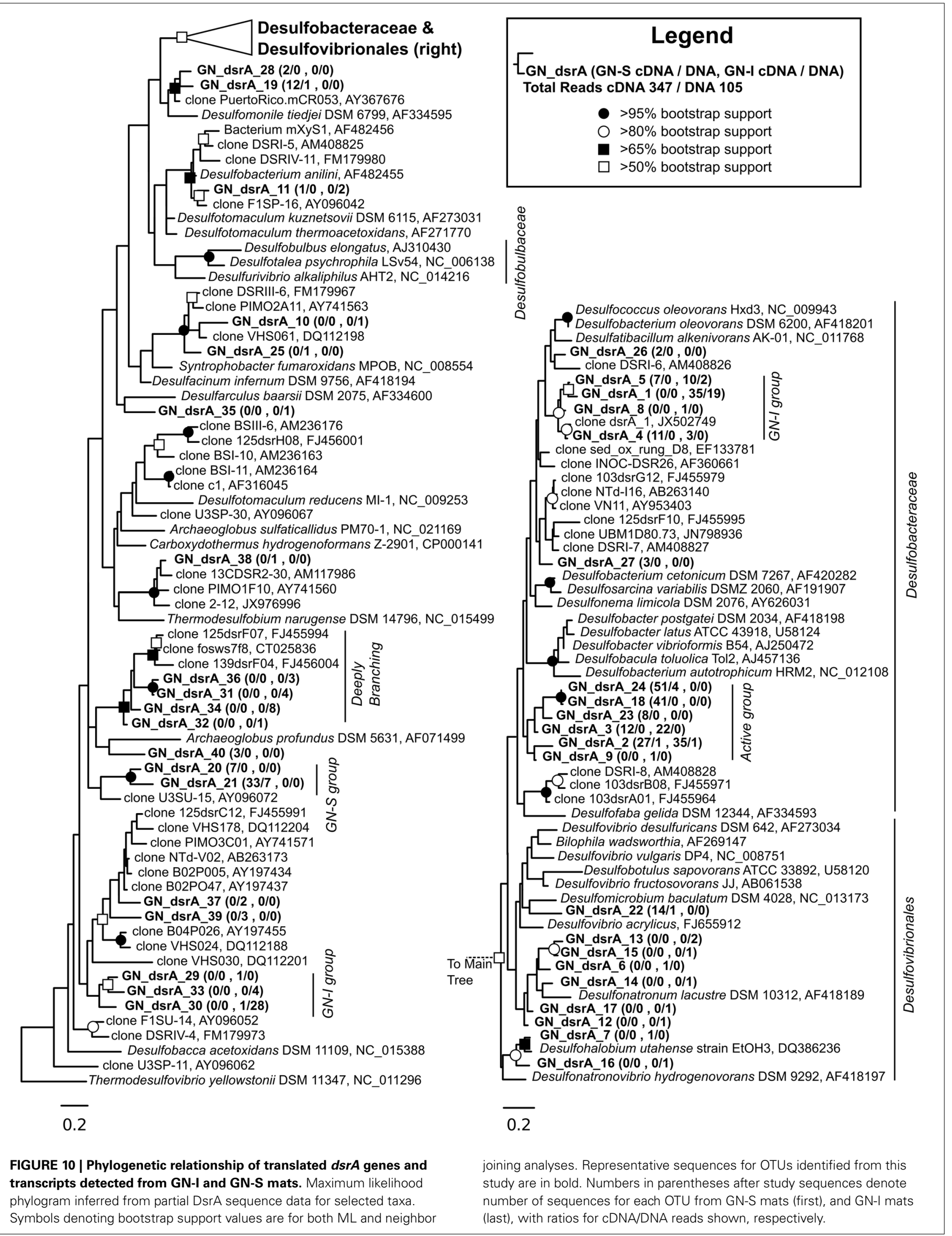


Photosynthetically-fixed carbon was indicated to be the feedstock for fermentation. In GN-I mats, enhanced levels of bicarbonate incorporation (Figure 3) were reflected in significantly higher net efflux of fermentation products than in GN-S mats (Figure 2). Indeed, when DCMU was used to limit oxygenic photosynthesis, net fermentation dropped more than in GN-S mats, indicating oxygenic photosynthesis in Cyanobacteria was the most likely cause behind net fermentation productivity of these mats. At the same time, NanoSIMS measurements of bicarbonate incorporation (Figure 4) show increased accumulation of label in GN-I Microcoleus filaments over GN-S filaments. These findings point to the accumulation of glycogen being more common in GN-S mats, but increased fixation and increased catabolic metabolism being more common in GN-I mats and fits the observation that GN-I mats are adapted to exist in a dynamic turbulent intertidal zone and GN-S mats are adapted to quiescence (Bebout et al., 1994).

Pyrotag assays (Figure 1) corroborated previous reports of the abundance (approximately one fourth of DNA sequences from pyrotag libraries) of Chloroflexi in GN-S mats (Ley et al., 2006) as well as a similar level of Chloroflexi pyrotags seen in GN-I mats. Moreover, previous studies have shown that anoxygenic phototrophy was found to account for $10-40 \%$ of carbon fixation in GN-S mats (Finke et al., 2013), assumed to be by phototrophic sulfide oxidation. It has also been demonstrated, in the case of hot springs microbial mats that filamentous photoautotrophic Chloroflexi can have a role in fermentation, including hydrogenase transcript expression at night (Klatt et al., 2013), or a role indirectly driving fermentation (Otaki et al., 2012). Yet, in this study anoxygenic phototrophy appears to play only a minor role in nighttime fermentation in Guerrero Negro mats. Expression ratio (cDNA:DNA pyrotags) data demonstrated that Cyanobacteria (specifically genus Microcoleus in GN-S mat and both Microcoleus and genus Lyngbya in GN-I mat) maintain a consistent level of ribosomal expression between day and night and at a level much higher than any other phylogenetic group detected. The only hydrogenases attributable to phototrophs that were expressed at night (Figure 5) were associated with Cyanobacteria; no type $3 \mathrm{~b}$ [NiFe]-hydrogenases from any anoxygenic phototrophic Chloroflexi group were recovered. However, given that marine filamentous anoxygenic phototrophs are diverse and mostly uncharacterized in Guerrero Negro mats (Nübel et al., 2001; Ley et al., 2006) the phylogeny of novel Chloroflexi hydrogenases present in these systems is an avenue of future study. But overall, given the dominance of several types of Cyanobacteria in pyrotags and hydrogenase transcripts, Cyanobacteria were likely the metabolically dominant phototrophic fermenters in mats. Interestingly, the HoxH tree (Figure 5) does suggest that a Cyanobacteria other than Microcoleus chthonoplastes PCC 7420 was the main hydrogen producer in GN-S mats and that different species of Cyanobacteria may differ in their capacity for hydrogen production.

Under natural conditions, both the GN mats and Elkhorn Slough mats (Burow et al., 2012) were characterized by net fluxes of hydrogen and organic acids out of the mats at night due to fermentation activity. However, in mats incubated with DCMU for the previous photoperiod, net hydrogen fluxes were reduced relative to the unamended treatments, whereas the flux of organic acids out of the mats was not significantly different (Figures 2C,D), This differential effect of DCMU on hydrogen vs. organic acid flux was not previously observed in Elkhorn Slough samples (Burow et al., 2012). Overall, though the DCMU in mats has been shown to inhibit photosystem II in Cyanobacteria and the establishment of anoxic conditions, the response of whole mat communities to this photosystem shutdown in daylight was variable across different mat types and is still poorly understood, especially with respect to the daytime sulfide cycling. Mechanisms in both Cyanobacteria and in Cyanobacteria-associated members, such as phototrophic sulfide oxidation, may be acting in concert to alter both the cycling of hydrogen as well as the original production of hydrogen.

\section{HYDROGEN AND ORGANIC ACID AVAILABILITY LEADS TO UPTAKE BY CYANOBACTERIA-ASSOCIATED MICROBES IN HYPERSALINE MICROBIAL MATS}

Release of cyanobacterial fermentation products within the closely packed matrix of the mat offers a flux of potential substrate to a range of terminal metabolizers. We hypothesized that SRB were the primary consumers of hydrogen and organic acids under dark, anoxic conditions, due to the abundance of sulfate. Like in hot spring microbial mats (Otaki et al., 2012) they were suspected to require close physical proximity for hydrogen uptake. In GN-I mats, inhibition with molybdate significantly increased accumulation of hydrogen at quantitatively similar levels to physical disruption (Figure 8B). This was consistent with previous findings in the hypersaline microbial mats of Elkhorn Slough (Burow et al., 2012), and suggests that a physical association between Cyanobacteria and SRB underlies most of the observable consumption of fermentation products within these mats (Burow et al., in press). Molybdate also enhanced accumulation of hydrogen in the GN-S mats, but physical disruption in those mats did not result in significantly greater net hydrogen flux relative to controls (Figure 8D). Thus, while SRB appear to be the dominant sink for fermentation products under dark conditions in GN-S mats, physical associations appear to be less important than in the GN-I and Elkhorn Slough mats, though there is evidence that physical proximity could still be necessary (Fike et al., 2008). However, the failure of physical disruption techniques to separate mat members apart in GN-S mats cannot be discounted, nor can the possibility of unique motile SRBs in GN-S mats be discounted.

We show here that disruption of the GN-I microbial mat, with a presumed separation of diverse members of the mat community from Cyanobacteria, led to a proportionally greater increase in the flux of organic acids, relative to hydrogen. This was consistent with the idea that organic acid consumption was also dependent (and possibly even more dependent than hydrogen) on tight physical association between producing and consuming organisms. Preliminary efforts were made to identify organisms that may be consuming acetate, via NanoSIMS analysis of samples incubated with ${ }^{13} \mathrm{C}$-labeled acetate under dark/anoxic conditions. NanoSIMS analysis (Figure 9) confirmed that filamentous members of Chloroflexi and Desulfobacteraceae were significant consumers of acetate at night and may be 
important members of these close spatial associations, though no known filamentous SRB could be identified in DsrA phylogenetic analysis. Pyrotags of Proteobacteria show that purple nonsulfur bacteria were also quantitatively important, particularly in the GN-I mats (Figure 1B). The present study did not specifically investigate acetate uptake by these organisms. However, the diverse and robust nature of the metabolism within this group (with various members being able to conduct autotrophic, heterotrophic, photosynthetic, chemotrophic, aerobic, and anaerobic metabolisms) suggests that they should also be examined for significant nighttime consumption of fermentation products in GN-I mats.

\section{CONCLUSION}

In this study, a suite of methods identified that a variety of Cyanobacteria were the dominant fermentive organism responsible for hydrogen production during nighttime constitutive metabolism. Furthermore, hydrogen production was driven by daytime carbon storage, and total hydrogen produced was a fraction of the total fermentation potential, with the majority of fermentation products being organic acids (especially acetate). This work also identified uptake of acetate during nighttime by both sulfate reducing bacteria and filamentous Chloroflexi provided an important linkage to Cyanobacteria. Taken together, these results indicate the nighttime fermentation of stored light energy can explain the close association of the filamentous Chloroflexi and of the SRB with cyanobacterial filaments.

\section{ACKNOWLEDGMENTS}

We thank Erich Fleming, Angela Detweiler, Guillaume LamarcheGagnon, Daniel Albert, and Christina Ramon for technical support. We thank Jeff Cann, Associate Wildlife Biologist, Central Region, California Department of Fish and Game for coordinating our access to the Moss Landing Wildlife Area to collect Elkhorn Slough mats and Andrew McDowell at UCB for IRMS analyses. Funding was provided by the US Department of Energy (DOE) Genomic Science Program under contract SCW1039. Work at LLNL was performed under the auspices of the U.S. Department of Energy at Lawrence Livermore National Laboratory under Contract DE-AC52- 07NA27344. R. Craig Everroad acknowledges the support of the NASA Postdoctoral Program, administered by Oak Ridge Associated Universities through a contract with NASA.

\section{SUPPLEMENTARY MATERIAL}

The Supplementary Material for this article can be found online at: http://www.frontiersin.org/Journal/10.3389/fmicb. 2014.00061/abstract

\section{REFERENCES}

Abascal, F., Zardoya, R., and Posada, D. (2005). ProtTest: selection of best-fit models of protein evolution. Bioinformatics 21, 2104-2105. doi: 10.1093/bioinformatics/bti263

Albert, D. B., and Martens, C. S. (1997). Determination of low-molecular-weight organic acid concentrations in seawater and pore-water samples via HPLC. Mar. Chem. 56, 27-37. doi: 10.1016/S0304-4203(96)00083-7

Altschul, S. F., Gish, W., Miller, W., Myers, E. W., and Lipman, D. J. (1990). Basic local alignment search tool. J. Mol. Biol. 215, 403-410. doi: 10.1016/S00222836(05)80360-2
Anumula, K. R. (1994). Quantitative determination of monosaccharides in glycoproteins by high-performance liquid chromatography with highly sensitive fluorescence detection. Anal. Biochem. 220, 275-283. doi: 10.1006/abio. 1994.1338

Bahr, M., Crump, B. C., Klepac-Ceraj, V., Teske, A., Sogin, M. L., and Hobbie, J. E. (2005). Molecular characterization of sulfate-reducing bacteria in a New England salt marsh. Environ. Microbiol. 7, 1175-1185. doi: 10.1111/j.14622920.2005.00796.x

Bebout, B. M., Carpenter, S. P., Des Marais, D. J., Discipulo, M., Embaye, T., Garcia-Pichel, F., et al. (2002). Long-term manipulations of intact microbial mat communities in a greenhouse collaboratory: simulating earth's present and past field environments. Astrobiology 2, 383-402. doi: 10.1089/153110702762470491

Bebout, B. M., Fitzpatrick, M. W., and Paerl, H. W. (1993). Identification of the sources of energy for nitrogen fixation and physiological characterization of nitrogen-fixing members of a marine microbial mat community. Appl. Environ. Microbiol. 59, 1495-1503.

Bebout, B. M., Hoehler, T. M., Thamdrup, B., Albert, D., Carpenter, S. P., Hogan, M., et al. (2004). Methane production by microbial mats under low sulphate concentrations. Geobiology 2, 87-96. doi: 10.1111/j.1472-4677.2004.00024.x

Bebout, B. M., Paerl, H. W., Bauer, J. E., Canfield, D. E., and Marais, D. J. D. (1994). "Nitrogen cycling in microbial mat communities: the quantitative importance of N-fixation and other sources of $\mathrm{N}$ for primary productivity," in Microbial Mats NATO ASI Series, eds L. J. Stal and P. Caumette (Berlin; Heidelberg: Springer), 265-271.

Bebout, B. M., Paerl, H. W., Crocker, K. M., and Prufert, L. E. (1987). Diel interactions of oxygenic photosynthesis and N2 fixation (acetylene reduction) in a marine microbial mat community. Appl. Environ. Microbiol. 53, 2353-2362.

Bigge, J. C., Patel, T. P., Bruce, J. A., Goulding, P. N., Charles, S. M., and Parekh, R. B. (1995). Nonselective and efficient fluorescent labeling of glycans using 2-amino benzamide and anthranilic acid. Anal. Biochem. 230, 229-238. doi: 10.1006/abio. 1995.1468

Burow, L. C., Woebken, D., Bebout, B. M., McMurdie, P. J., Singer, S. W., PettRidge, J., et al. (2012). Hydrogen production in photosynthetic microbial mats in the Elkhorn Slough estuary, Monterey Bay. ISME J. 6, 863-874. doi: 10.1038/ismej.2011.142

Burow, L. C., Woebken, D., Marshall, I. L., Singer, S. W., Pett-Ridge, J., PrufertBebout, L., et al. (in press). Identification of Desulfobacterales as primary hydrogenotrophs in a complex microbial mat community. Geobiology.

Burow, L. C., Woebken, D., Marshall, I. P., Lindquist, E. A., Bebout, B. M., Prufert-Bebout, L., et al. (2013). Anoxic carbon flux in photosynthetic microbial mats as revealed by metatranscriptomics. ISME J. 7, 817-829. doi: 10.1038/ismej.2012.150

Caporaso, J. G., Kuczynski, J., Stombaugh, J., Bittinger, K., Bushman, F. D., Costello, E. K., et al. (2010). QIIME allows analysis of high-throughput community sequencing data. Nat. Meth. 7, 335-336. doi: 10.1038/nmeth.f.303

Castro, H., Reddy, K. R., and Ogram, A. (2002). Composition and function of sulfate-reducing prokaryotes in eutrophic and pristine areas of the florida everglades. Appl. Environ. Microbiol. 68, 6129-6137. doi: 10.1128/AEM.68.12.61296137.2002

Cline, J. D. (1969). Spectrophotometric determination of hydrogen sulfide in natural waters. Limnol. Oceanogr. 14, 454-458. doi: 10.4319/lo.1969. 14.3.0454

Des Marais, D. J. (1995). The biogeochemistry of hypersaline microbial mats. $A d v$ Microb. Ecol. 14, 251-274. doi: 10.1007/978-1-4684-7724-5_6

Des Marais, D. J. (2003). Biogeochemistry of hypersaline microbial mats illustrates the dynamics of modern microbial ecosystems and the early evolution of the biosphere. Biol. Bull. 204, 160-167. doi: 10.2307/1543552

Dhillon, A., Teske, A., Dillon, J., Stahl, D. A., and Sogin, M. L. (2003). Molecular characterization of sulfate-reducing bacteria in the guaymas basin. Appl. Environ. Microbiol. 69, 2765-2772. doi: 10.1128/AEM.69.5.27652772.2003

Engelbrektson, A., Kunin, V., Wrighton, K. C., Zvenigorodsky, N., Chen, F., Ochman, H., et al. (2010). Experimental factors affecting PCR-based estimates of microbial species richness and evenness. ISME J. 4, 642-647. doi: 10.1038/ismej.2009.153

Feazel, L. M., Spear, J. R., Berger, A. B., Harris, J. K., Frank, D. N., Ley, R. E., et al. (2008). Eucaryotic diversity in a hypersaline microbial mat. Appl. Environ. Microbiol. 74, 329-332. doi: 10.1128/AEM.01448-07 
Fenchel, T., and Finlay, B. J. (1995). Ecology and Evolution in Anoxic Worlds. Oxford; New York, NY: Oxford University Press.

Fike, D. A., Gammon, C. L., Ziebis, W., and Orphan, V. J. (2008). Micronscale mapping of sulfur cycling across the oxycline of a cyanobacterial mat: a paired nanoSIMS and CARD-FISH approach. ISME J. 2, 749-759. doi: 10.1038/ismej.2008.39

Finke, N., Hoehler, T. M., Polerecky, L., Buehring, B., and Thamdrup, B. (2013). Competition for inorganic carbon between oxygenic and anoxygenic phototrophs in a hypersaline microbial mat, Guerrero Negro, Mexico. Environ. Microbiol. 15, 1532-1550. doi: 10.1111/1462-2920.12032

Gihring, T. M., Green, S. J., and Schadt, C. W. (2012). Massively parallel rRNA gene sequencing exacerbates the potential for biased community diversity comparisons due to variable library sizes. Environ. Microbiol. 14, 285-290. doi: 10.1111/j.1462-2920.2011.02550.x

Guindon, S., Dufayard, J.-F., Lefort, V., Anisimova, M., Hordijk, W., and Gascuel, O. (2010). New algorithms and methods to estimate maximum-likelihood phylogenies: assessing the performance of PhyML 3.0. Syst. Biol. 59, 307-321. doi: $10.1093 /$ sysbio/syq010

Hall, P. O. J., and Aller, R. C. (1992). Rapid, small-volume, flow injection analysis for SCO2, and $\mathrm{NH} 4+$ in marine and freshwaters. Limnol. Oceanogr. 37, 1113-1119. doi: 10.4319/lo.1992.37.5.1113

Hamady, M., Walker, J. J., Harris, J. K., Gold, N. J., and Knight, R. (2008) Error-correcting barcoded primers for pyrosequencing hundreds of samples in multiplex. Nat. Meth. 5, 235-237. doi: 10.1038/nmeth.1184

Harrison, B. K., Zhang, H., Berelson, W., and Orphan, V. J. (2009). Variations in archaeal and bacterial diversity associated with the sulfate-methane transition zone in continental margin sediments (Santa Barbara Basin, California). Appl. Environ. Microbiol. 75, 1487-1499. doi: 10.1128/AEM. 01812-08

Hoehler, T. (2005). "Biogeochemistry of dihydrogen (H2)," in Metal Ions in Biological Systems, Volume 43 - Biogeochemical Cycles of Elements, eds A. Sigel, H. Sigel, and R. Sigel (Boca Raton: CRC Press), 9-48.

Hoehler, T. M., Bebout, B. M., and Des Marais, D. J. (2001). The role of microbial mats in the production of reduced gases on the early Earth. Nature 412 , 324-327. doi: $10.1038 / 35085554$

Ihaka, R., and Gentleman, R. (1996). R: a language for data analysis and graphics. J. Comput. Grap. Stat. 5, 299-314. doi: 10.1080/10618600.1996.10474713

Jones, D. T., Taylor, W. R., and Thornton, J. M. (1992). The rapid generation of mutation data matrices from protein sequences. Comput. Appl. Biosci. 8 , 275-282. doi: 10.1093/bioinformatics/8.3.275

Kaneko, R., Hayashi, T., Tanahashi, M., and Naganuma, T. (2007). Phylogenetic diversity and distribution of dissimilatory sulfite reductase genes from deepsea sediment cores. Mar. Biotechnol. 9, 429-436. doi: 10.1007/s10126-0079003-7

Keppler, D., and Decker, K. (1974). "Glycogen determination with amyloglucosidase," in Methods of Enzymatic Analysis, ed H. U. Bergmeyer (Weinheim: Verlag Chemie), 1127-1131.

Klatt, C. G., Liu, Z., Ludwig, M., Kühl, M., Jensen, S. I., Bryant, D. A., et al. (2013). Temporal metatranscriptomic patterning in phototrophic Chloroflexi inhabiting a microbial mat in a geothermal spring. ISME J. 7, 1775-1789. doi: 10.1038/ismej.2013.52

Kuczynski, J., Liu, Z., Lozupone, C., McDonald, D., Fierer, N., and Knight, R. (2010). Microbial community resemblance methods differ in their ability to detect biologically relevant patterns. Nat. Meth. 7, 813-819. doi 10.1038/nmeth.1499

Larkin, M. A., Blackshields, G., Brown, N. P., Chenna, R., McGettigan, P. A., McWilliam, H., et al. (2007). Clustal W and Clustal $\mathrm{X}$ version 2.0. Bioinformatics 23, 2947-2948. doi: 10.1093/bioinformatics/btm404

Le, S. Q., and Gascuel, O. (2008). An improved general amino acid replacement matrix. Mol. Biol. Evol. 25, 1307-1320. doi: 10.1093/molbev/ msn067

Leloup, J., Fossing, H., Kohls, K., Holmkvist, L., Borowski, C., and Jørgensen, B. B. (2009). Sulfate-reducing bacteria in marine sediment (Aarhus Bay, Denmark): abundance and diversity related to geochemical zonation. Environ. Microbiol. 11, 1278-1291. doi: 10.1111/j.1462-2920.2008.01855.x

Ley, R. E., Harris, J. K., Wilcox, J., Spear, J. R., Miller, S. R., Bebout, B. M., et al. (2006). Unexpected diversity and complexity of the guerrero negro hypersaline microbial mat. Appl. Environ. Microbiol. 72, 3685-3695. doi: 10.1128/AEM.72.5.3685-3695.2006
Li, W., and Godzik, A. (2006). Cd-hit: a fast program for clustering and comparing large sets of protein or nucleotide sequences. Bioinformatics 22, 1658-1659. doi: 10.1093/bioinformatics/btl158

Mussmann, M., Richter, M., Lombardot, T., Meyerdierks, A., Kuever, J., Kube, M., et al. (2005). Clustered genes related to sulfate respiration in uncultured prokaryotes support the theory of their concomitant horizontal transfer. J. Bacteriol. 187, 7126-7137. doi: 10.1128/JB.187.20.71267137.2005

Nübel, U., Bateson, M. M., Madigan, M. T., Kühl, M., and Ward, D. M. (2001). Diversity and distribution in hypersaline microbial mats of bacteria related to chloroflexusspp. Appl. Environ. Microbiol. 67, 4365-4371. doi: 10.1128/AEM.67.9.4365-4371.2001

Nübel, U., Garcia-Pichel, F., Kühl, M., and Muyzer, G. (1999). Quantifying microbial diversity: morphotypes, 16S rRNA genes, and carotenoids of oxygenic phototrophs in microbial mats. Appl. Environ. Microbiol. 65, 422-430.

Oettmeier, W. (1992). "Herbicides of photosystem II," in Topics in Photosynthesis, ed J. Barber (Amsterdam: Elsevier Science Publishers), 295-348.

Omoregie, E. O., Crumbliss, L. L., Bebout, B. M., and Zehr, J. P. (2004a). Comparison of diazotroph community structure in Lyngbya sp. and Microcoleus chthonoplastes dominated microbial mats from Guerrero Negro, Baja, Mexico. FEMS Microbiol. Ecol. 47, 305-308. doi: 10.1016/S01686496(03)00301-5

Omoregie, E. O., Crumbliss, L. L., Bebout, B. M., and Zehr, J. P. (2004b) Determination of nitrogen-fixing phylotypes in lyngbya sp. and microcoleus chthonoplastes cyanobacterial mats from Guerrero Negro, Baja California, Mexico. Appl. Environ. Microbiol. 70, 2119-2128. doi: 10.1128/AEM.70.4.21192128.2004

Ondov, B. D., Bergman, N. H., and Phillippy, A. M. (2011). Interactive metagenomic visualization in a Web browser. BMC Bioinformatics 12:385. doi: 10.1186/1471-2105-12-385

Oremland, R., and Capone, D. (1988). Use of specific inhibitors in biogeochemistry and microbial ecology. Adv. Microb. Ecol. 10, 285-383. doi: 10.1007/978-1-46845409-3_8

Otaki, H., Everroad, R. C., Matsuura, K., and Haruta, S. (2012). Production and consumption of hydrogen in hot spring microbial mats dominated by a filamentous anoxygenic photosynthetic bacterium. Microbes Environ. 27, 293-299. doi: 10.1264/jsme2.ME11348

Pett-Ridge, J., and Weber, P. K. (2012). "NanoSIP: NanoSIMS applications for microbial biology," in Microbial Systems Biology Methods in Molecular Biology, ed A. Navid (New York, NY: Humana Press), 375-408.

Reeder, J., and Knight, R. (2010). Rapidly denoising pyrosequencing amplicon reads by exploiting rank-abundance distributions. Nat. Meth. 7, 668-669. doi: 10.1038/nmeth0910-668b

Robertson, C. E., Spear, J. R., Harris, J. K., and Pace, N. R. (2009). Diversity and stratification of archaea in a hypersaline microbial mat. Appl. Environ. Microbiol. 75, 1801-1810. doi: 10.1128/AEM.01811-08

Rothrock, M. J., and Garcia-Pichel, F. (2005). Microbial diversity of benthic mats along a tidal desiccation gradient. Environ. Microbiol. 7, 593-601. doi: 10.1111/j.1462-2920.2005.00728.x

Skyring, G. W., Lynch, R. M., and Smith, G. D. (1989). "Quantitative relationships between carbon, hydrogen, and sulfur metabolism in cyanobacterial mats," in Microbial Mats: Physiological Ecology of Benthic Microbial Communities, eds Y. Cohen and E. Rosenberg (Washington, DC: American Society for Microbiology), 170-179.

Spear, J. R., Ley, R. E., Berger, A. B., and Pace, N. R. (2003). Complexity in natural microbial ecosystems: the guerrero negro experience. Biol. Bull. 204, 168-173. doi: $10.2307 / 1543553$

Steppe, T. F., and Paerl, H. W. (2002). Potential N2 fixation by sulfate-reducing bacteria in a marine intertidal microbial mat. Aquat. Microb. Ecol. 28, 1-12. doi: 10.3354/ame028001

Tamura, K., Peterson, D., Peterson, N., Stecher, G., Nei, M., and Kumar, S. (2011). MEGA5: molecular evolutionary genetics analysis using maximum likelihood, evolutionary distance, and maximum parsimony methods. Mol. Biol. Evol. 28, 2731-2739. doi: 10.1093/molbev/msr121

Vignais, P. M., and Billoud, B. (2007). Occurrence, classification, and biological function of hydrogenases: an overview. Chem. Rev. 107, 4206-4272. doi: $10.1021 / \mathrm{cr} 050196 \mathrm{r}$ 
Wagner, M., Roger, A. J., Flax, J. L., Brusseau, G. A., and Stahl, D. A. (1998). Phylogeny of dissimilatory sulfite reductases supports an early origin of sulfate respiration. J. Bacteriol. 180, 2975-2982.

Woebken, D., Burow, L. C., Prufert-Bebout, L., Bebout, B. M., Hoehler, T. M., PettRidge, J., et al. (2012). Identification of a novel cyanobacterial group as active diazotrophs in a coastal microbial mat using NanoSIMS analysis. ISME J. 6, 1427-1439. doi: 10.1038/ismej.2011.200

Zhang, W., Song, L., Ki, J.-S., Lau, C.-K., Li, X.-D., and Qian, P.-Y. (2008). Microbial diversity in polluted harbor sediments II: sulfate-reducing bacterial community assessment using terminal restriction fragment length polymorphism and clone library of dsrAB gene. Estuar. Coast. Shelf Sci. 76, 682-691. doi: 10.1016/j.ecss.2007.07.039

Conflict of Interest Statement: The authors declare that the research was conducted in the absence of any commercial or financial relationships that could be construed as a potential conflict of interest.
Received: 28 November 2013; paper pending published: 23 December 2013; accepted: 30 January 2014; published online: 26 February 2014.

Citation: Lee JZ, Burow LC, Woebken D, Everroad RC, Kubo MD, Spormann AM, Weber PK, Pett-Ridge J, Bebout BM and Hoehler TM (2014) Fermentation couples Chloroflexi and sulfate-reducing bacteria to Cyanobacteria in hypersaline microbial mats. Front. Microbiol. 5:61. doi: 10.3389/fmicb.2014.00061

This article was submitted to Microbial Physiology and Metabolism, a section of the journal Frontiers in Microbiology.

Copyright (C) 2014 Lee, Burow, Woebken, Everroad, Kubo, Spormann, Weber, Pett-Ridge, Bebout and Hoehler. This is an open-access article distributed under the terms of the Creative Commons Attribution License (CCBY). The use, distribution or reproduction in other forums is permitted, provided the original author(s) or licensor are credited and that the original publication in this journal is cited, in accordance with accepted academic practice. No use, distribution or reproduction is permitted which does not comply with these terms. 